\title{
Refining trip starting and ending locations when estimating travel-demand at large urban scale.
}

Krug Jean ${ }^{\mathrm{a}}$, Burianne Arthura ${ }^{\mathrm{a}}$, Bécarie Cécile ${ }^{\mathrm{a}}$, Leclercq Ludovic ${ }^{\mathrm{a}}$

Université Gustave Eiffel, Univ. Lyon, ENTPE, LICIT, F-69518, Lyon, France

\section{CORRESPONDING AUTHOR}

Leclercq Ludovic (ludovic.leclercq@univ-eiffel.fr)

\section{AUTHORS:}

Krug Jean ${ }^{1}$ : jean.krug@entpe.fr

Burianne Arthur²: arthur.burianne@entpe.fr

Bécarie Cécile: cecile.becarie@entpe.fr

Leclercq Ludovic: ludovic.leclercq@univ-eiffel.Fr

\section{FUNDINGS}

This work was supported by the European Research Council (ERC) under the European Union's Horizon 2020 research and innovation program [grant number 646592 - MAGnUM project].

\section{DECLARATION OF INTEREST}

None

\footnotetext{
${ }^{1}$ Permanent address: jean.krug.pro@gmail.com

2 Permanent address: arthur.burianne@,irt-systemx.fr
} 


\section{ABSTRACT}

Demand estimation is an important step for multiple applications in urban studies. However, the level of accuracy required depends on the objective of the study. In dynamic traffic microsimulation, the estimation of demand needs to be accurate, as it is intended to describe individuals' trips on a very small-scale. In this case, poor estimation of trip initiation, path, and endings could result in the wrong estimation of the city-block scale's traffic state. Estimating demand at a large-scale with high-resolution is not only very challenging because it requires a large volume of data from multiple sources, but the underlying mathematical problem is considerable and thus hard to solve.

In this paper, we address the issue of trip starts and ends when modeling large perimeters. We propose to enhance the location of trip initiation and termination by merging heterogeneous and large public datasets. To do so, we develop a series of algorithms that identify fine-mesh areas where trips could reliably start or end and we share the estimated demand within these sub-areas, following the distribution of trip purposes (Home, Work, Shop, etc.).

The method is deployed in Lyon city, France, and validated on an extraction of it. Microsimulation results show that the demand, once accurately distributed, changes the overall network's performance, confirming the significant influence of trip endings and starts on the overall traffic dynamics.

\section{KEYWORDS}

Urban Transportation; Demand Downscaling; Microscopic Simulation

\section{Introduction}

Estimating travel demand at the large urban scale is mandatory for multiple applications ranging from urban planning to traffic engineering and control (Jeon et al., 2012). To this end, one of the most reliable tools is the Four-Step Model (FSM). FSM consists of combining large datasets obtained through mobility surveys over large territories (Wegener, 2011). Its first step estimates the demand from suburban areas of different sizes, usually called Traffic Analysis Zones (TAZs), decomposed by trip purposes ("Home", "Work"...). The second step distributes this demand among the different destinations TAZs, creating the Origin-Destination (OD) matrix. The third step distributes the fluxes by mode (Car, Public Transports...), and the last step computes the assignment (Bonnel, 2002), i.e., the average flow during the peak hour in the different transportation networks (road, public transport,...).

Estimating Origin-Destination (OD) flows considering a spatial extent defined by the TAZs grid may be sufficient for some applications, like urban planning; other studies require a much finer description in space (Gurram et al., 2019). It is the case for agent-based and dynamic traffic simulations (Balmer et al., 2006), which are nowadays increasingly applied at the large urban scale for several reasons, such as (but not limited to):

- improving traffic management policies (Wegener, 2011),

- targeting specific commuters, or modeling the impact of small-scale interventions of identifying likely points of congestion (Lovelace et al., 2014),

- or quantifying the level of noise or air quality (Lund et al., 2020).

One of the significant consequences of aggregating data at a TAZ scale when dealing with micro-simulation is that the demand is not accurate enough to immediately define the scenario. A microscopic simulation needs to create and delete agents/cars at a specific location on the network and should then know precisely the trips starting and ending positions. Usually, the demand is randomly distributed among several entry/exit points in the TAZ from a central 
injector. However, when the vehicles appear or disappear inconsistently with the network characteristics, time-consuming manual adjustments are required to relocate the entry/exit points or rebalance the flow generation among them. Such actions usually go unnoticed in case study reports as it is part of the overall calibration process but the problem is well-known by traffic engineers that run simulations. The problem can be easily exemplified when considering a TAZ with heterogeneous building distribution. The road network matches the city building shape in real life, but the microscopic simulator does not have such information. Higher demand can then be generated where the building density is low and where the road network only offers low capacities. One most noticeable potential outcomes of inconsistent locations of trip starts and ends is congestion appearing at the wrong place or changes in the overall traffic dynamics due to incorrect distribution of vehicles over the network.

One solution could be to increase the number of TAZs and decrease their size to overcome this problem. However, this is not a universal solution because:

(i) It would require accurate socio-economic and mobility data available at a very small scale, almost at the individual scale, which is difficult and time-consuming to acquire.

(ii) It would result in very low fluxes between OD pairs, especially after disaggregating by purposes, and this is challenging to handle with micro-simulators.

Moreover, as stated by Lovelace et al. (2014), "Selecting zones that are too small relative to the study area can lead to long processing times, messy maps, and overcomplexity. Analyses based on overly large zones, on the other hand, can gloss over spatial variability by presenting space in extensive, homogeneous blocks."

To overcome the limitations related to the spatial resolution of the trip starting and ending locations provided by classical FSM methods, we proposed to add a $5^{\text {th }}$ step to the FSM framework. This step takes place between steps 2 (distribution) and 3 (mode choice) and deals with trip startings and endings' local positioning. This step does not require a more refined mesh, but instead, it further processes the available data inside each TAZ to apprehend trip terminations better.

The rest of the paper is organized as follows: first, the literature regarding FSM and its mains features (purpose distribution and zoning) is reviewed (Section 2). Section 3 presents the materials, in particular, all the data sources used in this study. Section 4 explains the methodology, i.e. how TAZs are partitioned into subregions and how trip starts and ends are accurately located by merging multiple data sources on buildings and their primary distinctions (housing, industry, education, etc.). Section 5 presents the case study applied for the city of Lyon, France, and Section 6 discuss the results obtained with the dynamic microsimulation.

\section{Literature Review}

The most classical method used to estimate travel demand in urban areas (although it is not the only option) is the four-step model (FSM). FSM originates from the microeconomic consumer choice theory applied in transportation research (see Bonnel (2002) for a review). It relies on partitioning the urban area into traffic analysis zones (TAZs) that constitute origins and destinations for trips. The FSM determines OD flow distribution among all the different TAZ. These models have already been widely documented for several decades (Manheim, 1979; Ben-Akiva and Lerman, 1985; Bonnel, 2002; McNally, 2007; Patriksson, 2015). Among the relevant studies, we can cite Dowd (2015), who applied an adapted FSM (MIT-FSM) to the Boston Metro Region to evaluate both the impact of flooding on a person's ability to complete 
trips and the overall performances of the network. Zhang and Levinson (2016) recently used an FSM to evaluate the evolution of network supply and travel demand associated with road infrastructure development at the microscale. Their study revealed that some network properties, such as road hierarchy, can be predicted at a large-scale.

While many studies estimate the demand at the TAZ level, some models propose to combine generic data calculated at the TAZ level with more accurate land-use data and Geographical Information Systems (GIS), providing information at a much smaller scale, to spatially refine the urban analysis (Paéz and Scott, 2004). Solutions for mapping these land-use data have been proposed, allowing an increase in the global amount of available data and a better location of activities. For example, Balmer et al. (2006) proposed a new demand-modeling framework that combines various data types (Household surveys, land-use data, commuting patterns, census data) to produce individual demand patterns. They applied their model to two areas. On the canton of Zürich, they mapped information on a raster with a grid cell size of 100 by $100 \mathrm{~m}$, resulting in a total of 167000 cells. A similar operation was carried on Berlin's city, resulting in 170000 cells of size 500 by $500 \mathrm{~m}$. Although the framework requires significant additional ressources compared to the original FSM, it constitutes a promising tool for aggregating/disaggregating multiples sources of data and dealing with a high number of agents (7 million people for Berlin).

To deal with the limited spatial accuracy of activities in classical models, Moeckel et al. (2002) also combined public data (among household surveys and census) aggregated at an administrative scale, with a land-use model (giving accurate information about density of housing, industries, open-spaces and other activities). First, they overlayed a raster of grid cell size 100 by $100 \mathrm{~m}$. Then, they estimated the distribution of activities provided by the land-use on this raster, increasing the resolution of the demand description to fit the needs for microsimulation, for example. However, it is important to notice that the authors discuss the relevance of using more disaggregated approaches, when considering the quantity of detailed data actually needed for these kind of studies.

Apart from coupling with land-use models, a significant concern, when dealing with FSM, is the question of trip purposes. Usually, purposes are estimated through the aggregation of various pre-existing datasets, such as socio-economic data, census, household surveys, landuse data (McNally, M.G., 2007).

However, as associating a purpose to each person's trips is a cumbersome task, and as activities chains are challenging to represent (because of the statistical under-representation of many purposes in the public surveys), studies often factor the data into a limited number of significant purposes. Thus, if Ghadiri et al. (2019) used five Home-Based purposes (Work, Education, Recreation, Shopping, and Personal business) when estimating travel demand for the city of Khoy, Iran, usually, these purposes are reduced to Home-Based to Work, HomeBased to Other, and Non-Home Based, with only a few variations (Zhao and Kockelman, 2000, 2002; McNally, M.G., 2007, Wang et al., 2013, Apronti and Ksaibati, 2018, Park et al., 2019).

Restricting possible trip purposes is a limiting factor to accurate positioning of trip starting and endings, crucial for micro-simulation studies.

Another aspect of FSM lies in using TAZs for travel demand estimation (Barton-Aschman Associates et al., 1997; McNally, M.G., 2007; Martínez et al., 2009, 2010; Jeon et al., 2012; Park et al., 2019). In FSM, TAZs are often reduced to a centroid, used as an injection point for vehicles (Horowitz, 2001; Qian and Zhang, 2012; Hagen-Zanker and Jin, 2015). This centroid is then connected to the real road network via one (or more) "centroid connector" or link, a virtual road for which artificial characteristics (capacity, maximum speed, travel time) are 
prescribed (Wang et al., 2013, Apronti and Ksaibati, 2018). However, although several centroid connectors sometimes ensure access to the TAZ from different locations, using a unique point for vehicle injection or removal can result in inconsistent local vehicle distributions because the demand injection is not enough correlated with the network properties. This is the case, for example, when an injection point uniformly distributes the demand to multiple subnodes where some are located in secondary network links that cannot sustain the flow generation because of limited link capacties. This is very problematic in the case of micro-simulation.

Supernak (1983) argued that the aggregation of data through a centroid, as it centralizes all the information, leads to a loss of accuracy (access to the public transport system, biases in the socio-economic characteristics of individuals leading to wrong mode sharing, etc.) which can affect the whole modeling process. Thus, some methods to avoid the use of these centroids have been developed. Using fine-grained spatial data, Manout et al. (2018) defined a new generation of centroids connectors, called stopping point connectors, accounting for the residents/workers' positions and the remoteness from transit facilities. Their method provides an increase in the model accuracy when compared with observed data.

Furthermore, the classical FSM framework globally ignores the intrazonal trips which compose a non-negligible part of travel demand (the OD matrix's diagonal terms). The quantity of intrazonal travel is estimated, but this demand is not projected on the real network as there is no step to position trip startings and endings accurately. Manout and Bonnel (2019) showed the importance of accurately representing the demand associated with these travel types. Their study, based on the comparison between different TAZ sizes, showed that misrepresentation of intrazonal trips significantly impacts network speed, volume, and congestion levels. Park et al., (2019), highlight that "Intrazonal trips are a minor consideration in the four-step travel demand modeling process, despite the fact that they typically amount to $10 \%$ or more of all trips in household travel surveys." In a recent study, Martínez et al. (2009) also estimated the level of intrazonal trips. Based on different TAZs shapes (from administrative to square grid), they estimated the percentage of intrazonal trips between $8 \%$ and $10 \%$.

Closely linked to centroids and intrazonal trips is the question of zoning, especially the shape and the size of TAZs (Manout and Bonnel, 2019). Although it has been under-considered for a while (Martínez et al., 2007), this point is crucial (Ding, 1998). The spatial extension of a TAZ directly impacts the number of intrazonal trips, the distance between zones, and the centroid's position and reliability. The finest zoning best represents the variability of trip distances, but it decreases the size of the sampling and the statistical reliability (Cabrera Delgado and Bonnel, 2016). Openshaw (1977), who compared different urban partitioning options through empirical experiments in the framework of spatial interaction models, showed that political or administrative zoning does not necessarily provide better results than randomized zoning. Ghadiri et al. (2019) confirmed this assertion by showing that TAZs of regular geometric shapes give the same quality level in trip production as traditional zoning. In their study, the mean TAZ area is $0.49 \mathrm{~km}^{2}$ (meaning about $700 \mathrm{~m}$ of characteristic length).

A long list of (sometimes contradictory) criteria for designing TAZ was established by Martínez et al. (2007). Their study clearly stated the difficulty of finding an optimal rule for shaping the TAZ, as there are many requirements (homogeneity, compactness, equity in terms of trip generation, minimization of intrazonal trips,...) that the TAZ should ultimately fulfill. Nevertheless, they proposed a numerical framework for TAZ design applied to the Lisbon Metropolitan Area (Martínez et al., 2009). Results of different TAZs designs systems (Administrative, Square grid, Smoothed density surface of geocoded travel demand data algorithm) were studied with respect to three indicators they tried to minimize: the percentage of intrazonal trips, the percentage of trips in statistically non-significant OD matrix cells, and the $75^{\text {th }}$ percentile of the zone equivalent radius in the subset of statistically significant zones. 
They concluded that grid cell and administrative-based designs were less accurate compared with their algorithm. In their studies, the TAZ equivalent radius evolved between $460 \mathrm{~m}$ and $1100 \mathrm{~m}$.

Altan and Ayözen (2018) also investigated the impact of TAZs sizes on their FSM accuracy when estimating Istanbul city's transport demand. By correlating the TAZ radius variation with the population and employment density, they showed that a decrease in TAZ size as the population density increases enhances the model accuracy. They found satisfying results when reducing the TAZ size to approximately $500 \mathrm{~m}$ mean radius, with a minimum limit of $350 \mathrm{~m}$ in central areas. When estimating the demand for the city of Berlin, Balmer et al. (2006) considered about $1000 \mathrm{TAZs}$ for about 12000 blocks. Each TAZ consists of several blocks. During their travel demand processing, they alternate aggregation and disaggregation steps within block-scale and TAZ-scale.

All these studies highlight the question of the complexity of TAZs sizes, although some indicators seem now to be globally accepted (zone compactness, homogeneity, size, number of the intrazonal trip). Especially, mean TAZ size is usually considered to be between $300 \mathrm{~m}$ and $700 \mathrm{~m}$ of characteristic length. However, we should stress that there is no clear aggrement about the best zone shape, which in any case highly depends on the data availability.

Considering all these aspects (especially the fact that intrazonal trips are usually poorly considered), the subject of trip data resolution becomes of significant importance.

Wegener (2011) considers that we should achieve a high resolution for traffic representation for any study "addressing environmental issues, such as air quality, noise, landscape." This is now possible considering the availability of new high-resolution datasets and enhanced capacities in computer science. For instance, Batterman et al. (2014) assess different spatial scales when estimating the level of exposure to Nitrogen Oxides (NOx). They conclude that considering spatial extents such as census tracts and ZIP codes instead of smaller areas leads to overestimating the exposure since fewer people live close by major roads. Gurram et al. (2019) use high-resolution data to investigate the pollutant concentration and air quality in the area of Tampa, Florida, and its effect on the population. Using DaySim as an activity-based model and Matsim for dynamic traffic assignment, they show that the mean level of exposition is better estimated with high-resolution data regarding both pollutant and traffic data. They use for locating activities and NOx concentration, a map scaled at $0.25 \mathrm{~km} 2$. They highlight that using a lower data resolution decreases the global exposure estimates. Also, dealing with exposure to micro-particles, Lund et al. (2020) combine an agent-based model with a map of PM2.5, to evaluate the impact of every-day activities for inhabitants in the region of Wasatch Front (Utah). Agents with "Home" and "Work" locations are described at census-block scale, meaning about 250 by $250 \mathrm{~m}$, and the PM2.5 concentration maps are generated at a spatial resolution of $250 \mathrm{~m}$. The authors underlined the problems of dealing with data sources from different periods, leading to variations between simulation results and observations. They conclude that studies requiring high-resolution data may be challenging to implement in more remote areas, where data is usually sparser and dispersed. This conclusion confirms Wegener's statement, saying that the counterpart of working at a microscopic approach when dealing with large perimeters is that it may lead to underestimating the complexity of the problem and the risk of getting lost in data collection and calibration.

These considerations highlight the need for high-resolution trip data, and it is even more crucial as public policies are now highly concerned about environmental issues (Pachaury et al., 2014).

The studies mentioned above highlight the importance of the initial partitioning on demand estimation. Also, they illustrate the difficulty of adjusting these parameters in practice (the 
number of regions) because it often depends on data resolution, which can vary from one dataset to another. Moreover, increasing the number of OD pairs (as required for a large-scale microsimulation) quickly complexifies the implementation.

The methodology proposed in this manuscript aims to take advantage of the FSM framework's numerous qualities while overcoming some of its limitations. Especially, FSM is very good at estimating the travel demand between extensive census or administrative areas. Coupling such estimations with a microscopic simulator makes it possible to get a global representation of individual trips, which is usually one of the significant challenges when modeling traffic demand (Balmer et al., 2006). However, while this guarantees that the number of trips between the TAZ corresponds to the FSM demand, a microscopic simulator requires additional information about the trip initiation and termination locations as this may influence the local traffic conditions.

Besides, the use of high-resolution spatial distribution of activities (specific datasets) allows us to get the origin and destination locations with high spatial accuracy (basically, at the building level) and still on the road network. It also avoids using any artificial centroid connector, as in many studies presented above, and thus promises a better representation of local phenomena.

Moreover, most studies are only dealing with a few trip purposes. Our framework can deal with a more extensive variety of travel purposes (up to nine in this study). This number is only limited by the statistical representativity of each purpose in the household surveys, meaning at a census scale. Our approach shows some similarities with the frameworks combining agentbased and land-use models (Balmer et al., 2006 ; Moeckel et al., 2002), as they also integrate land-use data. However, in our case, this integration takes place within the well-established and highly used FSM framework.

Thus, the methodology presented in this article can be seen as a fifth step added to the FSM that takes the original OD flow estimation between TAZs and transforms them into trips with the origin and destination locations inside the TAZ on the road network. Such locations are correlated with the local building shapes and activities and trip purposes. This is achieved by dividing the mesh originally described by urban policies (on which census and survey data are usually collected), called "IRIS" areas, into FM-IRISes sub-regions (for Fine-Mesh IRISes). Then, the description of the total regional trip starts and endings is distributed, over the FMIRISes and per purpose, to reflect the local information we have on building location and occupancy. Such a framework is tested in the city of Lyon, France. 


\section{Materials}

\subsection{Demand and geographical datasets}

Our framework requires several datasets. They are all summarized in Table 1 below. Each dataset is updated every year, except for the household survey (named EMD in this paper, for Enquête Ménages Déplacements in French), updated every ten years. Some of them are fully open-access, while others are free for research purposes only.

Table 1: List of databases used.

\begin{tabular}{|c|c|c|c|c|}
\hline Name & Source & Short description & Spatial Accuracy & Open-Access \\
\hline IRIS zoning & IGN & $\begin{array}{l}\text { Spatial Administrative } \\
\text { zoning. }\end{array}$ & IRIS & All \\
\hline $\begin{array}{l}\text { Répertoire } \\
\text { Immeubles } \\
\text { localisés }\end{array}$ & INSEE & $\begin{array}{l}\text { List of building } \\
\text { addresses, apartments, } \\
\text { and vacancy count. }\end{array}$ & $\begin{array}{l}\text { Postal address and } \\
\text { unique id }\end{array}$ & Research \\
\hline BD adresses & IGN & $\begin{array}{l}\text { Correspondence } \\
\text { between } \\
\text { addresses/unique id } \\
\text { and GIS location } \\
\text { coordinates. }\end{array}$ & $\begin{array}{l}\text { Postal address, } \\
\text { unique id and point } \\
\text { coordinates }\end{array}$ & Research \\
\hline BD Topo & IGN & $\begin{array}{l}\text { Geo-Referenced } \\
\text { Buildings. }\end{array}$ & $\begin{array}{l}\text { Shape and } \\
\text { coordinates }\end{array}$ & Research \\
\hline $\begin{array}{c}\text { Enquète } \\
\text { Ménage } \\
\text { Déplacement }\end{array}$ & $\begin{array}{l}\text { Quetelet } \\
\text { ADISP }\end{array}$ & $\begin{array}{l}\text { Household survey } \\
\text { focused on mobility. }\end{array}$ & $\begin{array}{c}\text { IRIS (or } \\
\text { aggregated IRIS) }\end{array}$ & Research \\
\hline Census & INSEE & $\begin{array}{c}\text { Population census and } \\
\text { description. }\end{array}$ & IRIS & All \\
\hline SIRENE & INSEE & $\begin{array}{c}\text { Record of all } \\
\text { companies in France, } \\
\text { main activity, and } \\
\text { employee count. }\end{array}$ & Postal address & All \\
\hline $\begin{array}{l}\text { Student } \\
\text { database }\end{array}$ & $\begin{array}{l}\text { National } \\
\text { Education }\end{array}$ & $\begin{array}{l}\text { Student count per } \\
\text { educational } \\
\text { establishment. }\end{array}$ & $\begin{array}{l}\text { By school and } \\
\text { highschool }\end{array}$ & Research \\
\hline $\begin{array}{c}\text { School } \\
\text { buildings } \\
\text { database }\end{array}$ & $\begin{array}{l}\text { National } \\
\text { Education }\end{array}$ & $\begin{array}{l}\text { School and high- } \\
\text { school location. }\end{array}$ & Point coordinates & All \\
\hline
\end{tabular}

\section{IRIS zoning:}

This corresponds to the spatial partitioning of an urban area based on the census of its inhabitants. IRIS ${ }^{1}$ gathers approximately the same number of residents, about 2000. Shapes and surfaces are highly variable. The smallest IRIS area covers 2 to 3 streets, but larger areas can cover several square kilometers (cf Figure 1, described later). In this study, TAZs are defined by our IRIS areas, and in the following, we refer to them as IRIS or IRIS areas.

\footnotetext{
${ }^{1}$ https://www.insee.fr/fr/metadonnees/definition/c1523
} 


\section{Répertoire Immeubles Localisés (RIL):}

This national database contains, for each building located in cities with more than 10000 inhabitants, the number of apartments and their vacancy. These data are updated by the French property tax institution (INSEE, 2016). The location of buildings is provided by the postal address and a unique identifier.

\section{BD adresses:}

This database, provided by IGN, the French national geographical service, matches postal addresses, and geographical coordinates. It uses the same identifiers as that of the RIL. Data coverage is very accurate in urban areas.

\section{BD Topo:}

Again, from IGN, this database provides us with a map of all buildings in France. Buildings are discretized depending on their usage (industry, agricultural, cultural, educational, etc.).

\section{Enquête ménage déplacement (EMD):}

This is the primary source of information on mobility behaviors. This survey describes the travelers depending on different aspects: socio-economic category (age, gender, etc.), main occupation (schoolboy, student, worker, retired, etc.), location of the home as well as the origin and destination purposes for all trips (home, work, leisure, studying and so forth).

In our case, this survey was carried on in 2015 and gathered information on 27000 residents' trips, from Monday to Friday. Over this 27 000, about 14000 underwent an interview at home (about 1h30). For the others, the survey was done by phone.

\section{Census:}

Through a continuous survey, census data is obtained by INSEE at the IRIS scale: each year, $10 \%$ to $15 \%$ of the IRIS inhabitants are surveyed. Data are merged and smoothed to get updated every five years. It is the primary source of population information.

\section{SIRENE:}

This file contains an accurate description of all official economic activities. This base is the result of a mandatory administrative declaration, and thus it is a highly reliable source of information.

The data is accurate enough to distinguish between different buildings of the same company, and it gathers not only significant companies but also associations and public administrations. It incorporates the postal address, the kind of activity, and the number of employees. This file is a major asset as it provides data at a high resolution (i.e., postal address). It has already been used for some transportation studies like freight transport modeling (Toilier et al., 2018).

\section{Student and School Building databases:}

The student base is an exhaustive census of all schoolboys and students in the different buildings. The School Building database allows us to locate them efficiently. These bases were completed by a phone survey carried out for this study, especially regarding universities, which are sometimes missing.

\subsection{Four-Step Model (FSM)}


Our approach requires running first a classical four-step model to estimate the OD flows per purposes at the TAZ scale. Our contribution is about improving the OD flow distribution inside the TAZ with a better description of the trip start and end locations. We should stress that our method does not change the flow estimation between TAZs, which is directly predicted by the original FSM.

Such an improvement is operated by adding a new sequence between the usual step 2 (trip distribution) and step 3 (mode choice) that focuses on refining local origins and destinations for trips considering additional data at the building level. Step 1 (trip generation) and step 4 (trip assignment) do not change either. In this study, we will extract the data from the FSM framework after step 2. This means that we assume that the results of phase 1, i.e., the travel demand per purpose at the IRIS scale, and step 2, i.e., OD flows between zones, are known. Note that emission represents the total number of trips starting in an area, while attraction is the total number of trips arriving in a zone. Among the different options proposed in the literature for step 2, we rely on the gravity model as it has already been successfully applied to the same territory, see Bonnel, 2002.

\subsection{Trip purposes}

FSM provides the travel demand in each IRIS area. In the following, emission from an IRIS area $i$ is denoted $E_{i}$, and attraction toward an IRIS area $j$ is denoted $A_{j}$. Additionally, emission and attraction can be associated with a given purpose, e.g., the number of employments, aka "Work" purpose, attracting or releasing workers. In this case, they are respectively denoted $E_{i}^{l}$ and $A_{j}^{l}$, where $l$ is the purpose. The people leaving IRIS area $i$ for their job are associated with an emission $E_{i}^{\text {work }}$.

The full list of purposes presented in the EMD household survey gathers 38 different categories. However, most of them are not statistically significant. They are, therefore, aggregated into 11 purposes, described in Table 2.

Table 2: List of purposes and their associated activity

\begin{tabular}{ll}
\hline Purpose & Associated activity \\
\hline Home & Apartment, House \\
\hline Work & $\begin{array}{l}\text { Any official company name (French SIRET description): } \\
\text { company, association, public service }\end{array}$ \\
\hline School & Elementary School \\
\hline College & High School \\
\hline University & University, Engineering school \\
\hline Shop & $\begin{array}{l}\text { Any private commercial venture (market, car dealer, } \\
\text { shop, etc.) }\end{array}$ \\
\hline Health & Medical, Para-medical, Hospital, etc. \\
\hline Medical \& Administrative steps & Administration, Social services \\
\hline Leisure & Museum, Theater, Sport, Concert hall... \\
\hline Escort & Bringing someone to a destination \\
\hline Visit & Visiting someone \\
\hline
\end{tabular}




\section{Method}

As mentioned in the introduction, in FSM, demand is estimated at the IRIS (TAZ) scale, and all information is usually concentrated at its centroid. Let recall here that OD flows are extracted after step 2 using FSM.

In this section, we present the two methods we implemented to circumvent the limitations highlighted in the introduction of this article:

1. A better location of trip generation and termination at the IRIS scale

2. An efficient correlation of these trips with origin and destination purposes, reflecting the activity existing in the IRIS.

\subsection{Localization of trip initiation and termination}

The more extended and heterogeneous the IRIS, the lower the accuracy in terms of traffic representation. Concerning this point, Supernak (1983) suggested that the best shape (for an IRIS) should satisfy the following conditions: (i) limitation of spatial data dispersion, (ii) reliable statistical sampling with acceptable computation time, and (iii) homogenization of area shapes. In our case, most of the information on traveler behavior is self-consistent at the IRIS scale.

However, although IRIS fulfills many of Supernak's requirements, the reliability of trip initiations and terminations can be jeopardized because of non-homogeneous building distribution within the IRIS. This example is illustrated in Figure 1 below, for the city of Lyon, France. Close to the city center, some IRIS areas are small and densely built (Figure 1a), while others have vacuums with no buildings where trips cannot be initiated or terminated (Figure 1b). Away from the city center, some IRIS combine both inhomogeneity and sparse building (Figure 1c and Figure 1d).

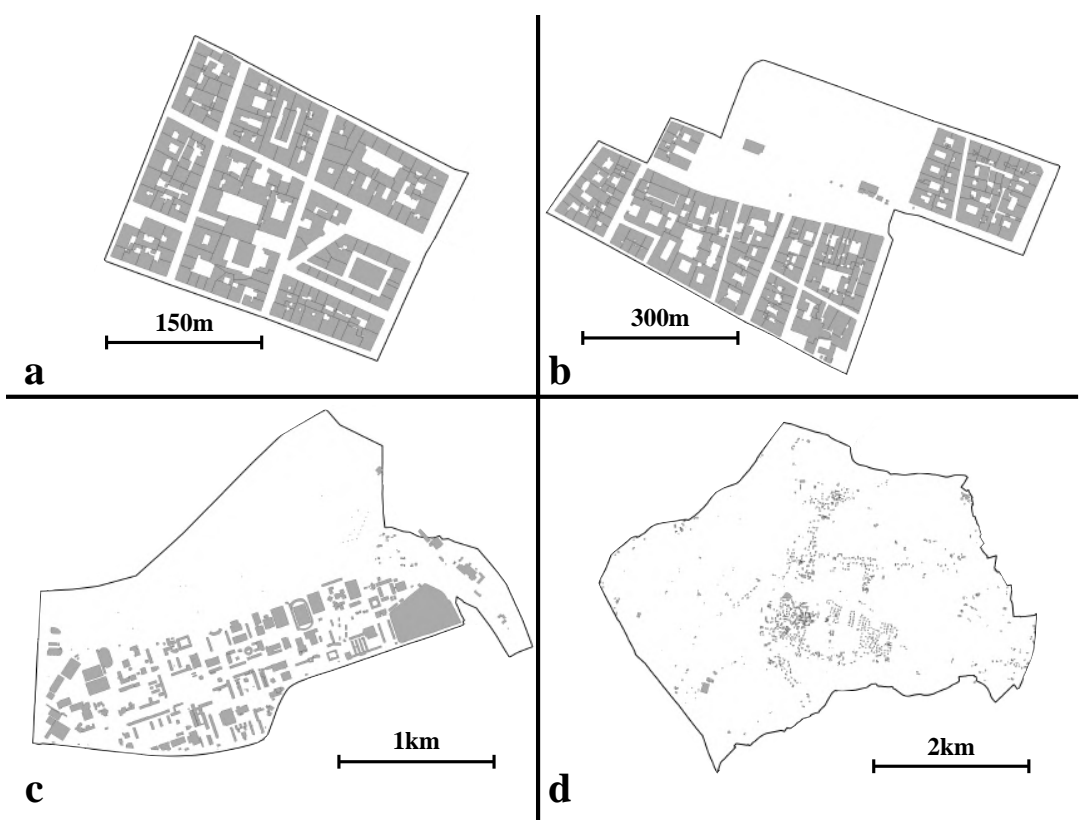

Figure 1: Building inhomogeneity in some IRIS areas (marked out with black lines) for the city of Lyon, France. IRIS a and b are downtown when $\mathrm{c}$ is located at the northern limit of the city. 
The IRIS described in d is located in the countryside. Note the variation in the size of each IRIS area.

To tackle the question of heterogeneous building distribution, we created an algorithm to identify sub-regions inside an IRIS area with dense enough building coverage. This algorithm, fully described in Figure 2, functions as follows.

1. First, to save time, the buildings described in the BD Topo are localized at their center of gravity with a centroid instead of a polygonal shape. A square mesh is then created, covering the full macro-perimeter, with a grid cell size of $70 \mathrm{~m}$. Previous studies involving land-use mapping spread within a wide range of values for grid cell sizes, from 40 by $40 \mathrm{~m}$ for (Martinez, 2007) up to 100 by $100 \mathrm{~m}$ in Zürich and 500 by $500 \mathrm{~m}$ for Berlin (Balmer et al., 2006). This grid cell size is small enough to ignore most nonbuilt areas and big enough to limit the computational time. This grid is then intersected with the building localization to identify the grid cells containing buildings.

2. Visual control is performed to ensure that no building is missed due to the previous simplification. If this is the case, the parameters (e.g., the grid cell size) can be adjusted.

3. During this process, some vacuum areas can appear between close buildings, even when they are part of the same structure. To avoid these phenomena, we create a $3 * 3$ cell moving matrix. This matrix glides from cell to cell and gathers the areas with continuous buildings inside. This is consistent with the definition of "built" given by INSEE, as "continuous buildings without space longer than $200 \mathrm{~m}$ ", The $3 * 3$ cell matrix is $210 \mathrm{~m}$ wide and thus conforms to this official definition.

4. At this point, the clusters of cells are identified.

5. The shape of the built area is then defined by following the centers of each border cell.

6. We then add a buffer layer one cell wide to perfectly encompass the surface covered by the buildings.

7. Finally, built areas that are smaller than a given size are disregard. The size of this threshold is $40000 \mathrm{~m}^{2}$ (meaning a characteristic length of $200 \mathrm{~m}$ ). This threshold was arbitrarily set as an equilibrium between accounting for the higher number of buildings and saving computational time. However, it is in the range of the smallest sizes recommended in the literature for TAZs (Sect. 2 Literature Review). Although this threshold deserves a further sensitivity analysis, it is still useful, mainly in the countryside, to avoid the multiplication of very small areas. (see Figure 1d).

\footnotetext{
${ }^{2}$ https://www.insee.fr/fr/metadonnees/definition/c1501
} 

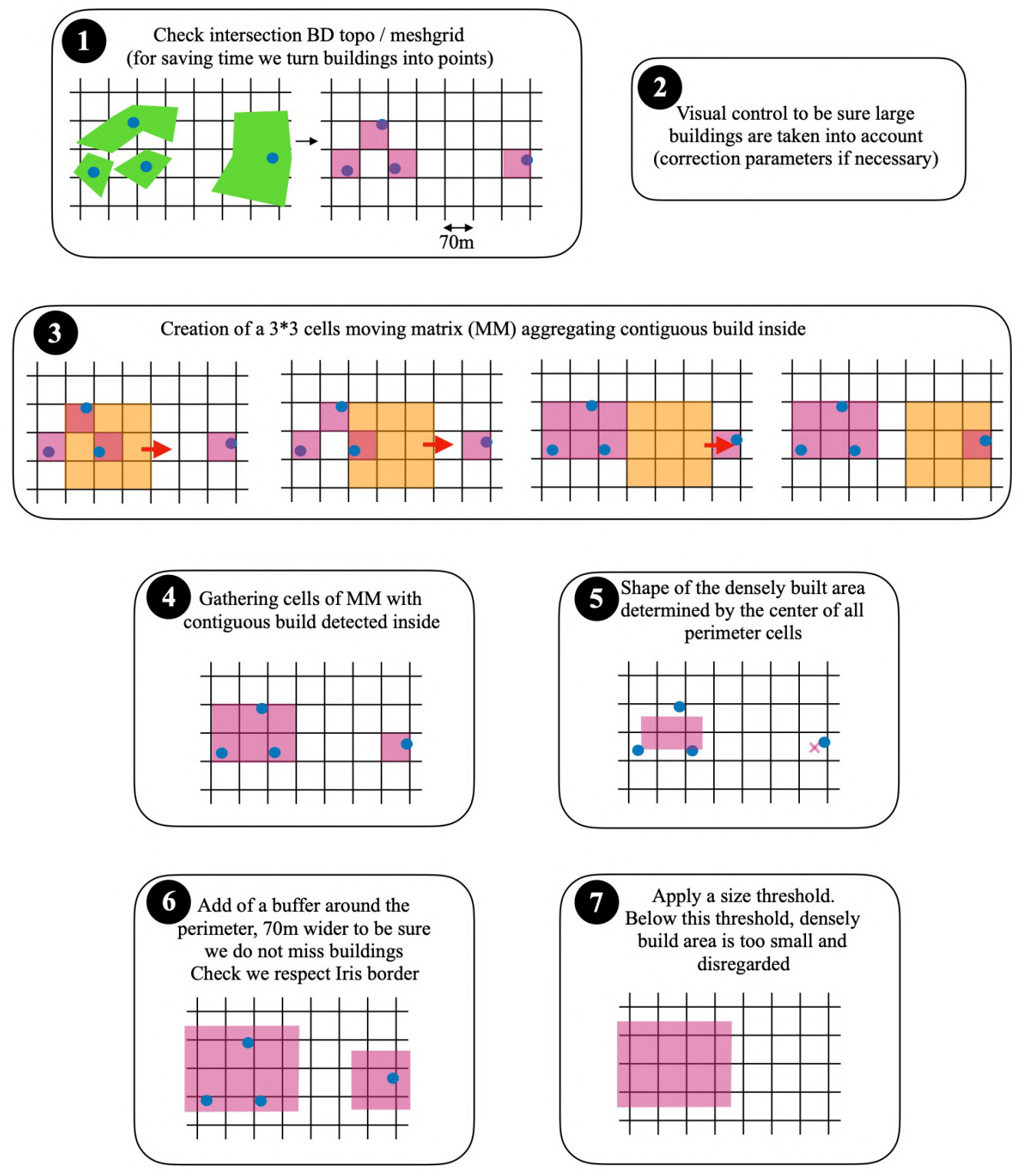

Figure 2: Description of the built detection algorithm.

An illustrated example of this algorithm is given in Figure 3 for Lyon St Exupery airport's IRIS area. The airport and the neighboring towns are recognized, isolated, and indexed. Uncultivated or agricultural areas, rivers, natural areas, and isolated buildings are ignored.

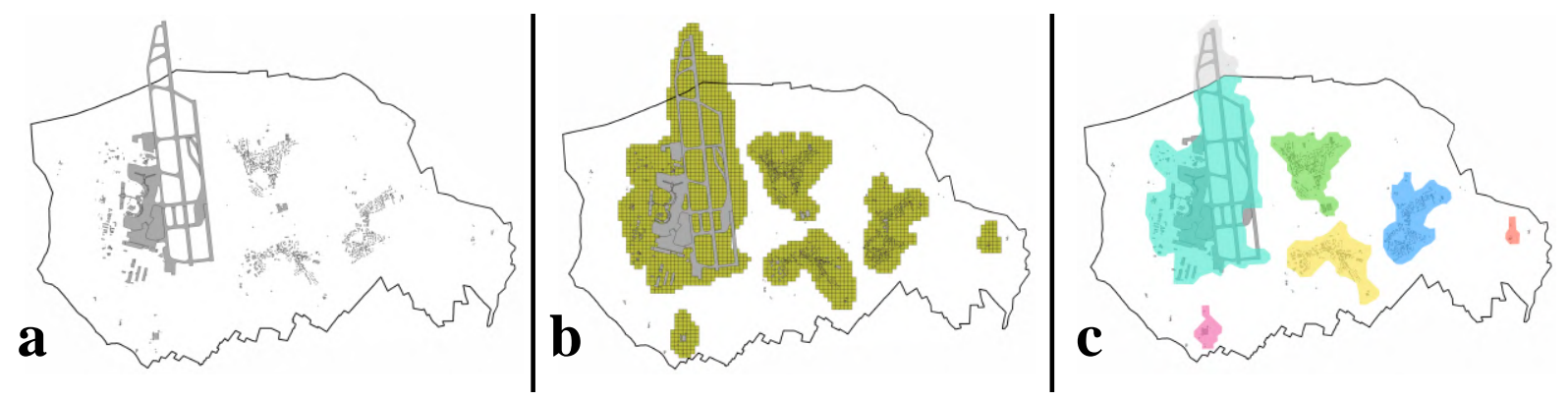

Figure 3: Illustration of the built recognition algorithm in the area of Lyon Saint-Exupéry Airport. For each IRIS (black line), the built area (a) is identified (b) and isolated in distinct areas (c). The algorithm is described in Figure 2. 
It is important to recall that this algorithm looks for building coverage. Thus, some non-built areas, such as parks or outdoor working areas, may be omitted. This must be taken into consideration when these cases are not marginal. However, in dense urban perimeter, this kind of situation is hardly encountered.

\subsection{Spatial distribution of purposes and trips}

At this stage, for a given IRIS, we know where OD trips should not start or end because there is no local origin or destination (vacuum identified by the previous algorithm). Still, we do not yet have a sufficient description of where trips should start and stop. We propose to exploit our dataset to improve the location of activities. The idea is that a trip with an origin purpose corresponding to "Home" should not be initiated from a commercial area but residential buildings, with a higher probability if such facilities have more inhabitants.

\subsubsection{FM-IRIS sub-division}

It makes sense to distribute the purposes at a refined scale, as most of our datasets are given at the scale of postal addresses. Thus, we decided to partition the built area defined in the previous paragraph into sub-regions named "FM-IRIS", for Fine-Mesh IRIS. The algorithm is described in Figure 4 below:

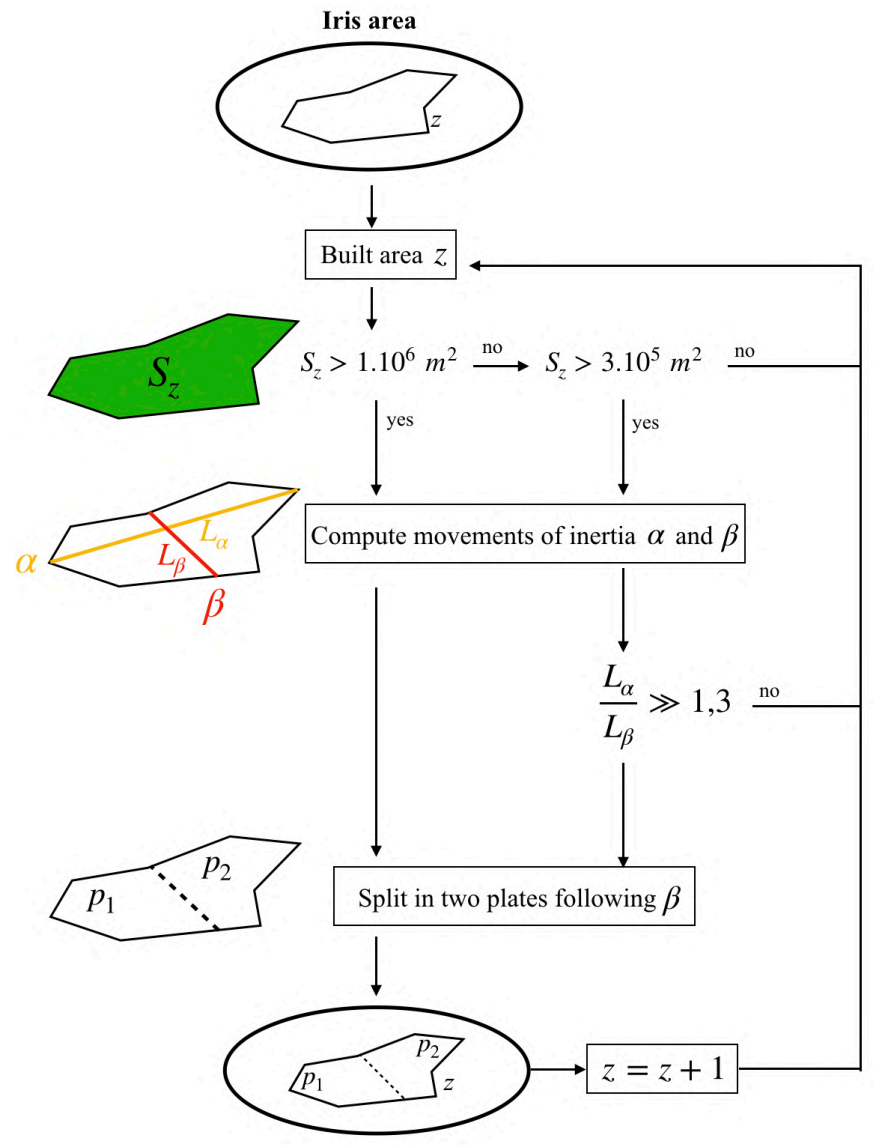

Figure 4: Description of the algorithm of FM-IRIS sub-division. $\boldsymbol{S}_{\boldsymbol{z}}$ is the surface of the built area $\boldsymbol{z}$, and $\boldsymbol{L}_{\boldsymbol{\alpha}}$ and $\boldsymbol{L}_{\boldsymbol{\beta}}$ are length of axis defined by the two movements of inertia $\boldsymbol{a}$, and $\boldsymbol{\beta} \cdot \boldsymbol{p}_{\mathbf{1}}$ and $\boldsymbol{p}_{\mathbf{2}}$ are the resulting FM-IRISes. 
The surface of the built area $\left(S_{z}\right)$ is computed and compared with a threshold value of $1.10^{6} \mathrm{~m}^{2}$. We choose this value of $1.10^{6} \mathrm{~m}^{2}$ as a compromise between two requirements : (i) reaching a total number of FM-IRISes which keeps the computational time as low as possible and (ii) getting a distribution of sizes and shapes for FM-IRISes, as small and homogeneous as possible. Then, there are two possibilities:

1. If the surface is larger than the threshold, it must be split, whatever the area's shape. We calculate the two first movements of inertia of the built area, $a$, and $\beta$. The FM-IRIS is split along the axis defined by the shortest movement of inertia $(\beta)$.

2. If the surface is smaller than the threshold, it will not be split, except if the following conditions are fulfilled:

○ $S_{Z}$ must be larger than $3.10^{5} \mathrm{~m}^{2}$ (meaning, about $500 \mathrm{~m}$ characteristic length). This threshold was set to ensure we keep homogeneous purposes within a reliable area and not considering the building scale.

- The ratio between the length of the first two movements of inertia $\left(\frac{L_{\alpha}}{L_{\beta}}\right)$ must be higher than 1.3. This means that even if the built area is too small to be split, its shape is still well spread and can be improved. In this case, as previously, the FM-IRIS is divided along the axis defined by the shortest movement of inertia $(\beta)$.

Following the statement of Martínez et al., 2009, according to whom "irregular geometry boundaries zoning system should present better results compared to an equivalent regular geometry boundary zoning system", and although some additional sensitivity tests should be carried on concerning the threshold used during this spatial disaggregation process, we still fulfill the majors' recommendations listed in the literature review. Our splitting mainly follows the administrative zoning and respects the compactness and the size homogeneity.

\subsubsection{Quantifying purposes at the FM-IRIS scale}

The FSM allows us to compute the demand and the OD flux, per purpose, at the IRIS scale. But, in our case, we rely on our new dataset to further localize them accurately at the FM-IRIS scale. The way we proceed in localizing purposes using the dataset is described below, for each purpose.

Note that, as children under age 6 are usually escorted by a person in charge, we decided to gather all the trips associated with this class into an "escort" purpose.

\section{"Home" purpose:}

We use the "Census" dataset to get the residential population at the IRIS scale. Then, the "RIL (Répertoire Immeubles Localisés)" is used to identify the size of residences (houses, flats per building), and the "BD Adresses" to distribute this purpose spatially by transforming postal addresses into geographical coordinates.

\section{"School" and "College" purpose:}

The "Student" database gives capacities of schools and colleges. The "School Building" databases provide the location of schools and colleges. These data are associated with an accurate geo-localization, giving the position at the building level.

Data concerning private schools are obtained manually by phone survey. 


\section{"University" purpose:}

Capacities and location of some establishments are obtained the same way as we did for "School" and "College" purposes. As the data available is sparser due to the number of private universities and engineering schools, we mainly contracted a phone survey to get the number of students and the exact location. Although some of them can be missing, combining these two approaches gives a precise representation of the location and a reliable numbering of this purpose.

\section{"Work", "Shop", "Health", "Medical \& Administrative steps", and "Leisure" purposes:}

The SIRENE (list of all official economic activities) dataset identifies all buildings (at street scale) for which a professional activity has been declared. It also associates an ID corresponding to each type of activity identified. The correspondence between these ID and human-readable activities is realized using the NAF classification (ex: ID "45.11" means "Cars Sellers"). We then relate the activity to one or several purposes (Shop, Leisure...), following Table 3 below:

Table 3: Correspondence between NAF codes and purposes

\begin{tabular}{cc}
\hline Purpose & NAF classification \\
\hline Work & All \\
\hline Shop & Any shop, including “car and truck sellers" \\
\hline Health & Any activity for human health \\
\hline Medical \& Administrative steps & Public \& defense administration \\
& Mandatory social security \\
Leisure & Creative \& artistic activities \\
& Libraries, museums, and other cultural activities \\
& Gambling and money organization \\
& Sports \& recreational activities \\
\hline
\end{tabular}

For the estimation of purpose in each building, we rely on the number of employees, given by range in Table 4 below, and we process the purpose as follows:

- For "Work", we directly get the number of employees by class using Table 4. This information allows the highly accurate quantification of "Work" purpose, which is a significant source for mobility;

Table 4: Number of employees in the SIRENE database for each class.

\begin{tabular}{|l|}
\hline Number of employees by class \\
\hline 0 \\
\hline $1-2$ \\
\hline $3-5$ \\
\hline $6-9$ \\
\hline $10-19$ \\
\hline $20-49$ \\
\hline $50-99$ \\
\hline $100-199$ \\
\hline+100 for each additional class \\
\hline
\end{tabular}


- For "Shop", "Health", "Leisure", and "Medical and Administrative Steps", the process is a little bit different. We know the demand $E^{l}$ for purpose $l$ at the MacroPerimeter scale. We know the exact distribution of "Work" purposes at the IRIS and FM-IRIS scale from the previous step. We then compute the fraction of workers associated with purpose $l$ in FM-IRIS $k$, denoted $w_{F M_{k}}^{l}$ (for example, when dealing with purpose "Shop", we only consider the employees working in structures "Any shop, including car and truck sellers" in Table 3). The number of purpose $l$ in FMiris $k$ is then equal to the product of $E^{l}$ and $w_{F M_{k}}^{l}$.

Thus, the number of entities for these purposes is directly linked to the workers in the related domains and estimated at the FM-IRIS scale. This approach is simple to implement, does not require a specific algorithm, and considers that one building can host several purposes (different SIRENE classifications).

Finally, locations (given as a postal address in the SIRENE file) are projected into geographic coordinates using the "BD Adresses" dataset.

While giving satisfying results, this method can still raise biases: for example, the Public Administration of Lyon has declared all its employees in only one place (the central town hall), whereas, in reality, they are dispatched to different locations around the city. Hopefully, these cases are marginal and can be corrected manually.

Moreover, this process always associates the same number of purposes for a given number of employees, although they should sometimes lead to different attraction levels. For example, a theatre may correspond to one worker ("Work" purpose) but two hundred customers ("Leisure" purpose), while a sports coach may correspond to one worker for one customer. This limitation could be circumvented by creating an abacus and corresponding tables, but this has not been implemented in our model yet.

Finally, we would like to point out that, as our framework does not consider a trip origin or destination within an area that is not built, some structures are disregarded. Especially, the purpose "Leisure" may be underestimate, especially for public parks and gardens. However, we consider that most of the travels to parks are done by public transport, walk, and bike, and thus, do not really impact our study, as we, finally, consider cars only.

Nevertheless, some strategies could be deployed to address this specific question. One of them would be to combine a manual survey (as we did for "University") with the postal addresses of the main park entrances.

\section{Escort purpose:}

The "Escort to destination" purpose is turned into ratios computed directly from the EMD household survey.

The purpose "Escort to bus stop" has not been considered here. Although it is included in the EMD, for the city of Lyon, it gathers only 441 trips against 8600 for "Escort to destination" and 40000 for "Home". Moreover, it would require the use of additional data regarding public transport lines and stops.

\section{Visit purpose:}

We do not know how these trips share between the different possible locations (home, work, leisure, etc.). Thus, we hypothesized that $80 \%$ of the "Visit" trips are for journeys home and $20 \%$ for work. 
At this stage, our purpose locations are known at the postal address, and we can compute each purpose's distribution over the different FM-IRIS (see Figure 5a), thus permitting to initiate/terminate the right trip at the correct location. This distribution is normalized at the IRIS scale, and it is denoted $p_{k}^{l}$, where $l$ is the purpose and $k$ the FM-IRIS number, such as:

$$
\sum_{k=1}^{n} p_{k}^{l}=1
$$

where $n$ is the number of FM-IRISes in the IRIS area.

The number of trips initiating and terminating in each FM-IRIS is obtained by the product of the ratios $p_{k}^{l}$ and the emission $E_{i}^{l}$ and attraction $A_{i}^{l}$, respectively (Figure 5b). Each purpose is processed independently. This distribution respects the vacuum inside the IRIS but also the variation in built coverage.
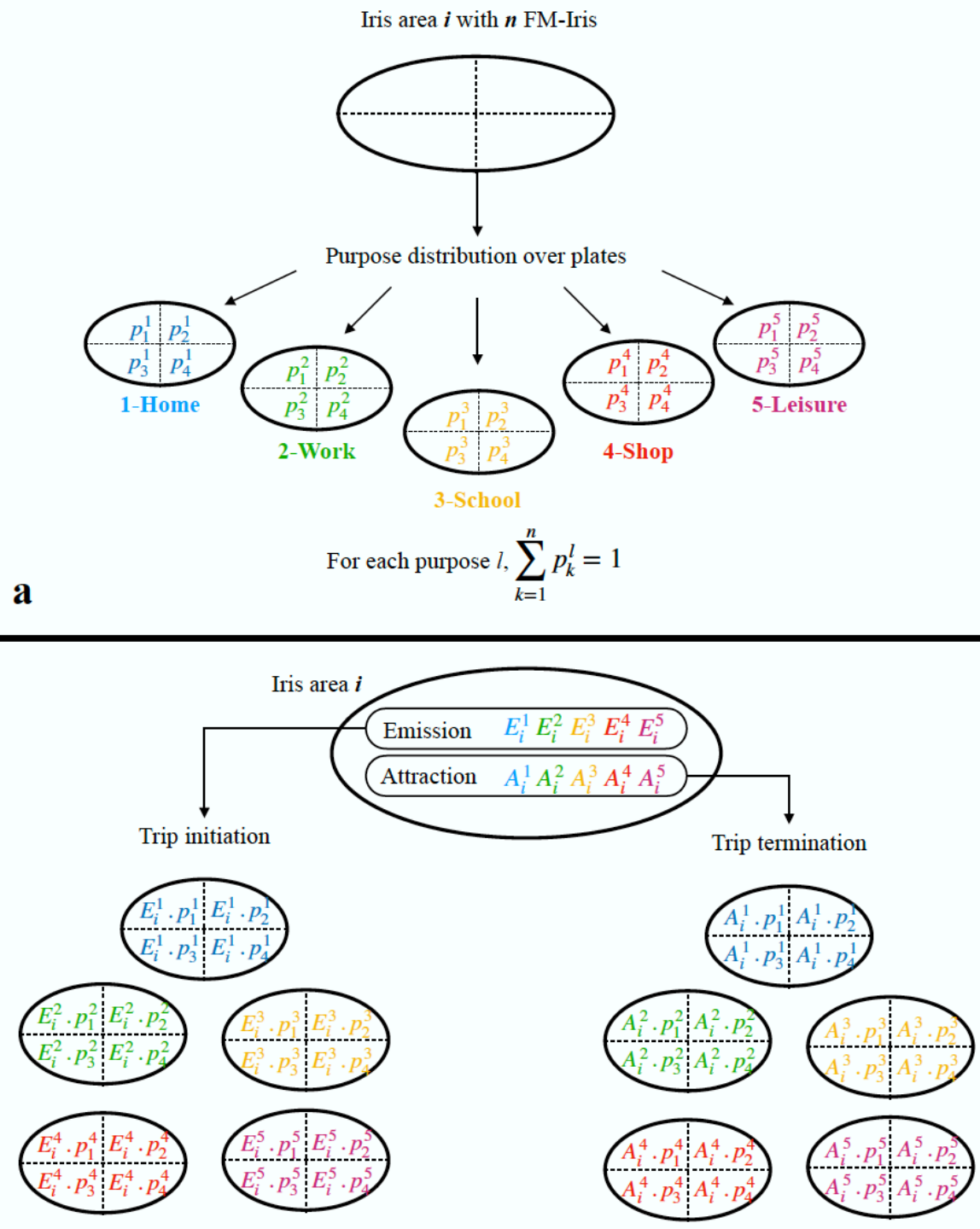

b

Figure 5: Description of the purpose localization algorithm. For a given IRIS area $i$, defined with $n$ FM-IRIS (in this example, $n=4$ ). Here, the example is shown with five purposes only (unique color code). (a) Distribution of purposes $\boldsymbol{p}_{\boldsymbol{k}}^{l}$ at the FM-IRIS scale, where $l$ is the purpose 
and $k$ the FM-IRIS number. (b) Distribution of emission $(E)$ and attraction $(A)$ over the FMIRIS, using the purpose coefficients computed above.

\section{Case Study}

\subsection{Description of study perimeters}

We decided to focus our study on the area of Lyon, France (see Figure 6.a). To carry out the simulation, we must capture all the traffic flows that occur in the network. We thus need to define two perimeters:

- The macro perimeter (i.e., the demand perimeter), on which the demand is estimated.

- The micro-perimeter (i.e., Lyon network), for which the simulation is assumed to run.

\subsubsection{Macro-perimeter}

This perimeter is the one for which the demand is calculated. It is larger than the microperimeter and encompasses it.

Designing the shape of this area is not straightforward. The demand estimation is calculated only for the inhabitants of this perimeter. Any trip by people living outside this perimeter is ignored. Thus, the perimeter must be large enough to capture all travelers' flux moving across the micro-perimeter. However, the area of this perimeter should not exceed the geographical scope of the EMD. Otherwise, this may lead to the extrapolation of the indicators defined from the EMD and thus distort the demand estimation.

Also, a significant concern is the border of the macro-perimeter. Border IRIS areas may attract or emit a significant part of fluxes. Thus, the border must be far enough from the microperimeter not to influence behavior close to it.

In our case, the demand perimeter contains 660 Iris areas and covers more than $2100 \mathrm{~km}^{2}$. This perimeter is shown in Figure $6 . \mathrm{b}$ and represented by a large circular area approximately $50 \mathrm{~km}$ in diameter.

It is important to specify that the macro-perimeter was designed by taking into account the daily mean travel distance traveled by a traveler to ensure that most of the trips are included in the demand. Moreover, we chose to integrate certain major urban polarities, as they may constitute large reservoirs of people working inside the micro-perimeter.

One limitation due to our definition of the macro perimeter is that we do not incorporate long-range transit (people crossing the macro-perimeter). This leads to the problem of underestimating this demand in the micro-perimeter. Hopefully, several highways are mainly used by vehicles to cross the macro-perimeter without entering the micro-perimeter. That is why the effect should be negligible in the final simulation. 


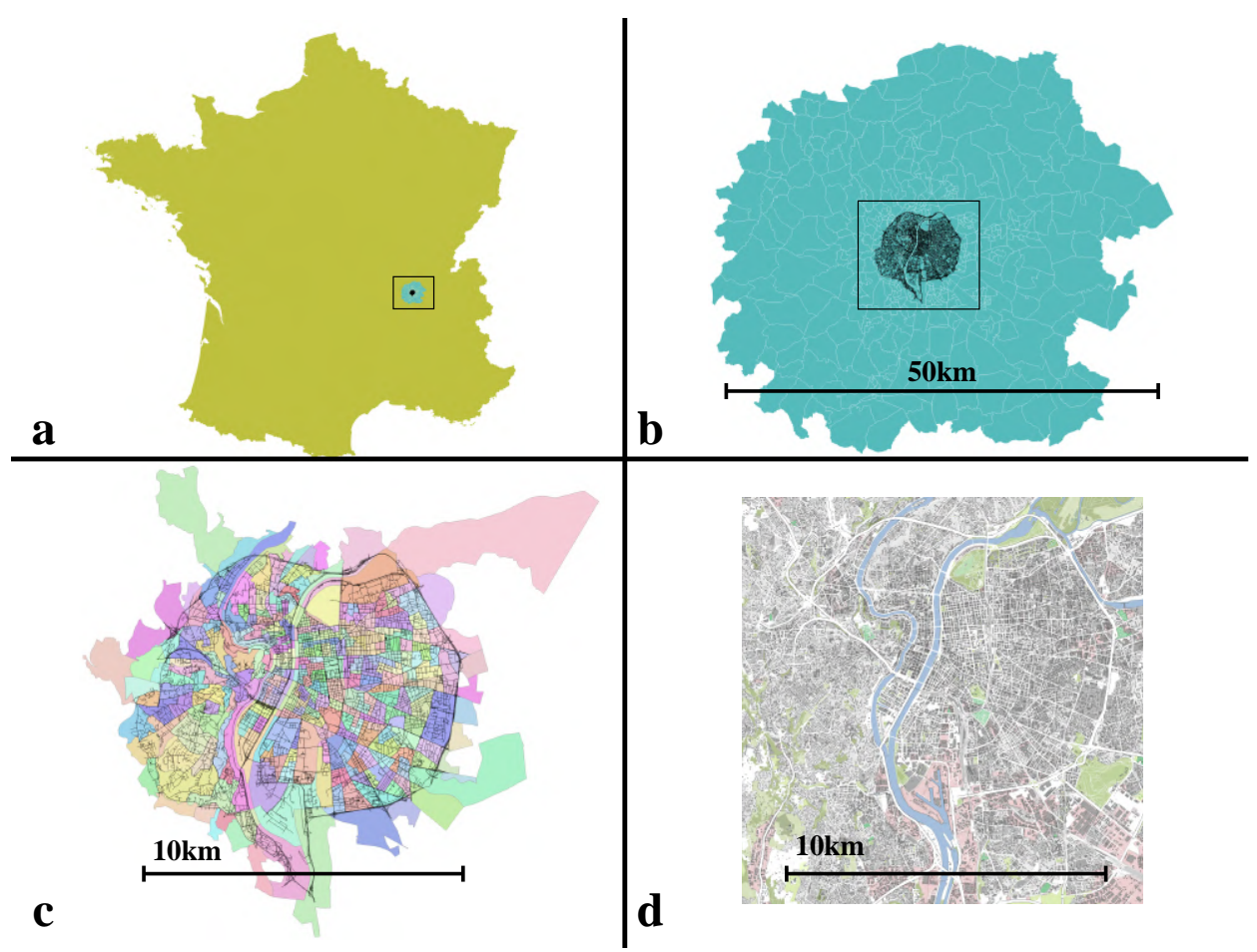

Figure 6: Study perimeters: (a) location of the study area in France, (b) macro-perimeter with micro-perimeter footprint in black, (c) micro-perimeter (network roads in black) with colored Iris, (d) micro-perimeter with land-use masks.

\subsubsection{Micro-perimeter}

Although the demand data is estimated at a larger scale, we focus only on inner Lyon (and its immediate districts).

In terms of inhabitants, Lyon is the third-largest city in France, and it is almost surrounded by a large ring road of $25 \mathrm{~km}$ length. This freeway facilitates the network's delimitation and allows better restriction of the incoming and outgoing fluxes (via highway interchanges) in any direction except the southwest. A large part of the town of Villeurbanne is included in the perimeter. On the west side, we incorporate Tassin-la-Demi-Lune city, Sainte-Foy-lès-Lyon city, and a section of Pierre-Bénite city. This network is referred to as "Lyon" in the following.

This network presents several interesting features (see Figure 6cd), such as high-capacity and a high-speed road (ring road), dense urban area, a quasi Manhattan Network and other areas with restrained capacities, such as bridges over the Saone and the Rhône rivers, and some residential areas with complicated access (south-western area).

The micro-perimeter (Figure 6c) gathers 286 IRIS areas with a surface area of $150 \mathrm{~km}^{2}$. Thus, $40 \%$ of the IRIS areas are located over $7 \%$ of the macro-perimeter. This high variability in population concentration highlights the disparity in demand estimation and the need for a proper demand estimation method.

Network data were provided by HERE Navstreets (http://navmart.com/here-navstreets/), which proposes a Geographical Information System (GIS) formatted data file describing the network of the Rhônes-Alpes area as observed in 2014. From this dataset, we extracted a footprint corresponding to the Lyon area (see Figure 6c). 


\subsection{Consequences of the new methodology}

When applying the algorithms described in Sect. 4 on the perimeters presented above, some local specificities arise. These are further described in the paragraphs below.

\subsubsection{Concerning the computation of FM-IRISes}

When appliying the built-detection algorithm (Sect. 4.1), we decided to locate trips origin and destination at the building center of gravity, instead than at the postal address or the position of main entrances or exits. This choice may have a consequence, especially for large buildings located on the border of a FM-IRIS, for which gravity center may be in a different FM-IRIS than real entrances or exits. However, in our macro-perimeter, the mean building size is about $217 \mathrm{~m}^{2}$, where the average FM-IRIS surface is approximately $334000 \mathrm{~m}^{2}$. Given these figures, associating a building to the wrong FM-IRIS is very unlikely. Additionally, in our framework, the largest built areas are cemeteries, representing negligible numbers of trips. Moreover, in the end, vehicles are injected into the road network. Thus, even if errors on trip start or end location are still possible, they are quite limited in practice.

Concerning the process of built area subdivision (Sect 4.2.1), on the macro-perimeter, it resulted in the design of a total of 2900 FM-IRISes. The final mesh is illustrated in Figure 7. We see that the FM-IRIS distribution is concentrated along the rivers flowing through Lyon (The Saône from north to south, the Rhône from north-east to south.), and the main freeways, as these areas are densely built.

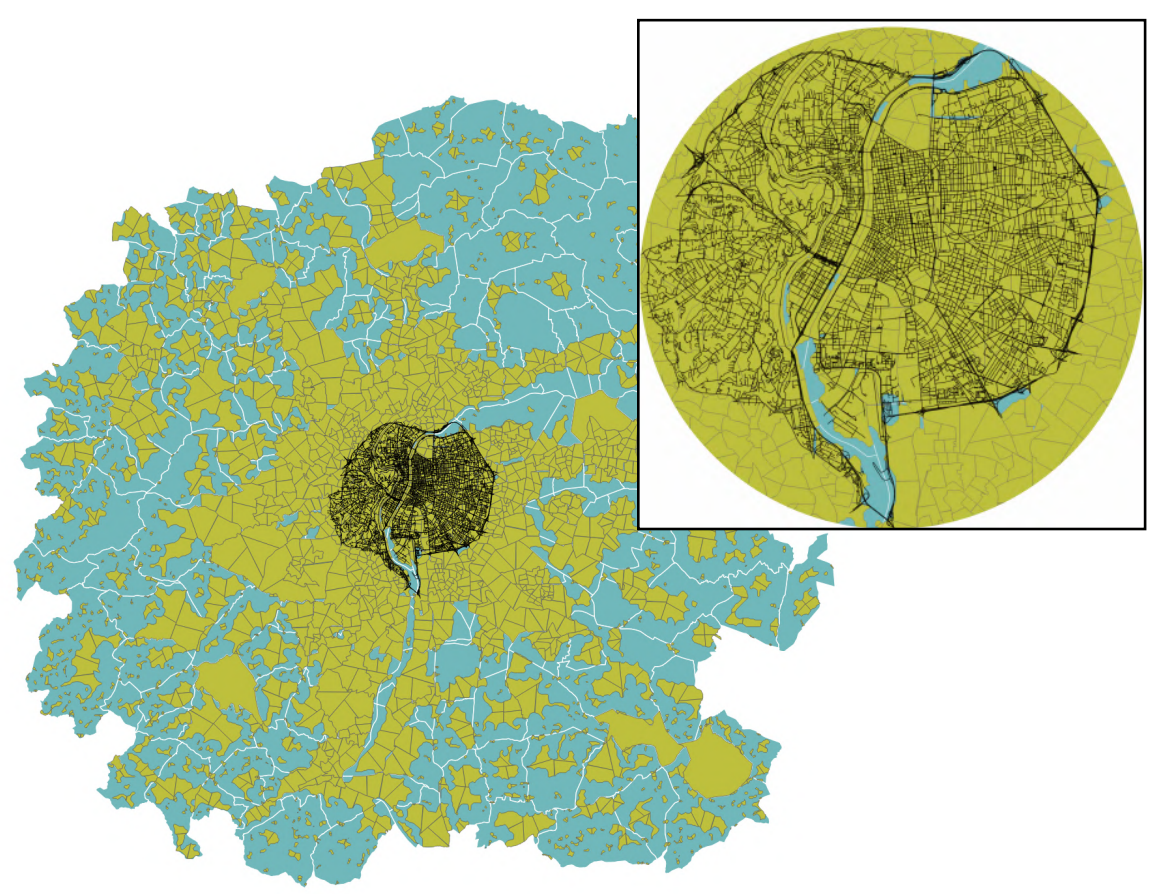

Figure 7: Illustration of the macro-perimeter. The IRIS mesh is shown in blue, the FM-IRIS mesh in green. For information, the micro-perimeter is over-printed in black. 


\subsubsection{Concerning the distribution of purposes}

When quantifying purposes at the FM-IRIS scale (Sect 4.2.2), the SIRENE dataset listed 55250 records on the Macro-perimeter. When relocating activities, our algorithm managed to locate $93 \%$ of the establishments at the IRIS scale and $92 \%$ at the FM-IRIS level.

An example showing the result of the whole process is given in Figure 8 and 9. In this example, we compared four IRIS areas with different features.

In Figure 8a, we consider an area called "Saxe-Bossuet", located downtown in a residential area. Our analysis shows that even if the two FM-IRISes are equivalent in shape, we can highlight some slight differences in the quantity and distribution of purposes. In particular, the "Shop" purpose is located almost only in FM-IRIS 2 (there are two supermarkets in this area). In contrast, the "Health" purpose mainly appears in FM-IRIS 1 (however, this must be compared with the absolute value of the "Health" purpose, which is insignificant). The absolute values of demand associated with each purpose highlight the high number of residential buildings. The number of trips in this area associated with purpose "Home" is more than 3000 , far ahead of the second primary purpose, "Shop", with approximately 2000 trips.

In Figure 8b, we focus on an IRIS area named "Tony Garnier" in Lyon's southern part. An unbuilt area corresponding to the Rhône river flowline can be seen on the west part of the area, detected by our built recognizer algorithm. The rest of the built coverage was split into four FM-IRISes, as homogeneous in shape as possible. When looking at the purpose distribution, we see much more variability than in the previous area. FM-IRIS 2 is the one with the highest ratio of "Leisure" purpose. This is explained by many sports facilities, including one of Lyon's largest stadiums, spotted by our algorithm. In total, this purpose gathers about 11000 trips per day. The residential buildings are mainly located in the northern part of the area, in FM-IRIS 1, where the purpose "Home" is the most represented. Purpose "Work" is shared between FMIRIS 1 and 2, which corresponds to reality because most of the offices are located in this area. We also note the Ecole Normale Supérieure (a French engineering school) in FM-IRIS 1 and several research laboratories in FM-IRIS 2, explaining the presence of a non-negligible number of trips for this purpose (1500 trips). The poor representation of FM-IRIS 4 is explained by the fact that most of the structures observed in this area are parks, and thus mainly aggregate a few trips associated with the purpose "Leisure". 


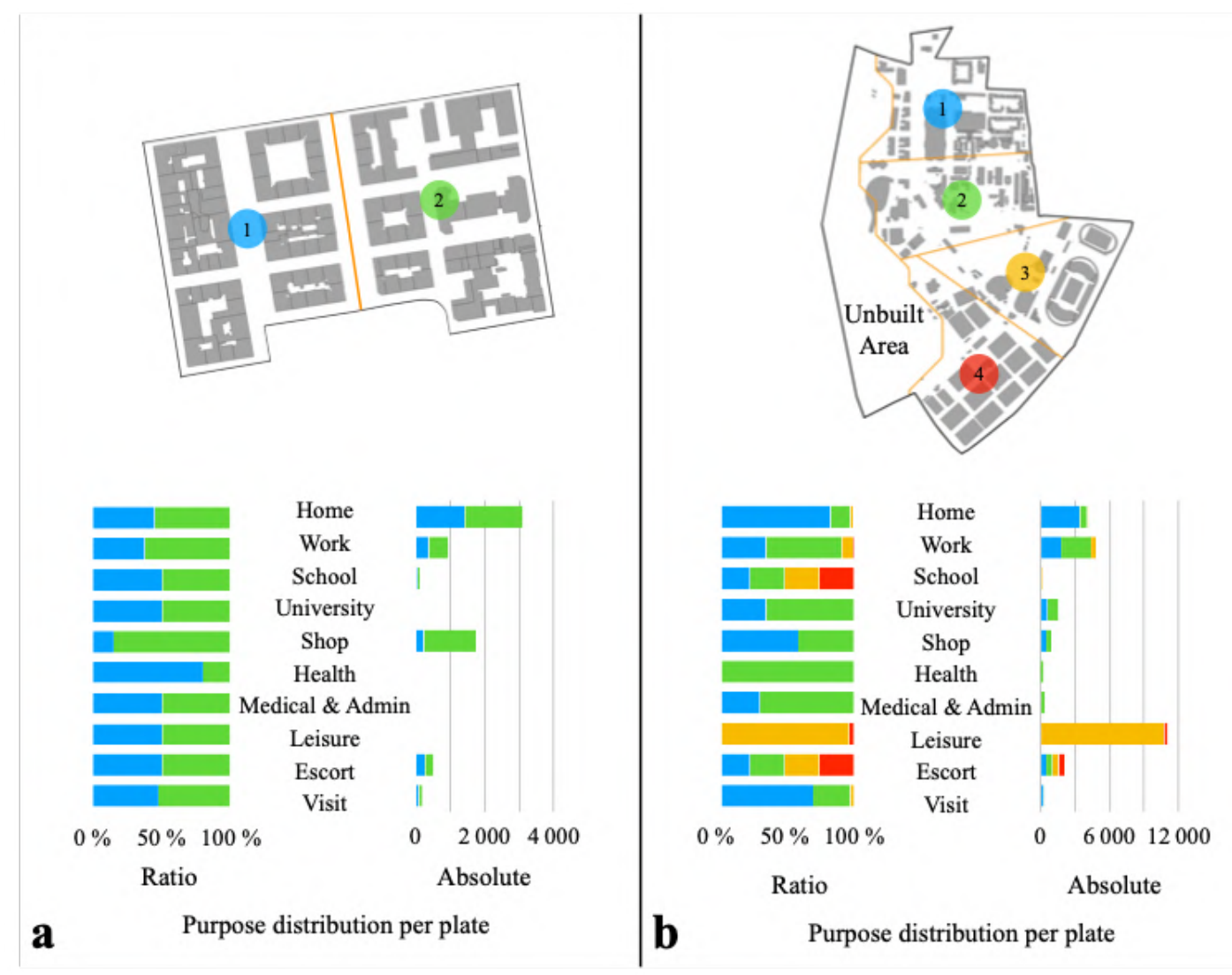

Figure 8: Results of the successive algorithms on two different areas: (a) "Saxe-Bossuet - a residential area, (b) "Tony Garnier" - a diverse area. Built is shown in dark gray, the orange line delimits FM-IRISes. The purpose distribution is also indicated as a ratio between the different FM-IRISes (left part of the graphs) and an absolute number of trips associated with the area (right part). The color code reflects different FM-IRISes.

In Figure 9a, we focused on a two FM-IRISes area located downtown south, at the two rivers' confluence. For this reason, there are two unbuilt areas. The sub meshing algorithm split this very heterogeneous area into two FM-IRISes. This area is dedicated to commercial purposes and leisure. In FM-IRIS 1 are localized a few residential buildings and the central part of Lyon's major retail centers, explaining the high level of "Shop" purpose (about 4000 trips). On the contrary, FM-IRIS 2 comprises museums, cultural centers, art galleries, and a circus. This is why the "Leisure" purpose is mainly localized in this FM-IRIS (85\% of the area), and its value very high (9444 trips).

The last IRIS area presented in Figure 9b is called "La Doua", and it is one of the leading student areas in Lyon. It is located in Lyon's northern part (see Figure 1c) and bordered at its northern part by the Rhône River. Thus, a large amount of this area is unbuilt and so ignored by the built-detection algorithm. The remaining part is split into four FM-IRISes. FM-IRIS 2 contains most of the "Home" purposes, which are composed of student housing. Areas 2 and 3 gather all the "Work" purposes. In contrast, the most representative purpose, "University", is shared almost equally between the four FM-IRISes, totalizing about 35000 trips, which corresponds to approximately $25 \%$ of the "University" trips listed in the macro-perimeter. The "Leisure" purpose is also shared homogeneously and gathers only 10000 trips. 


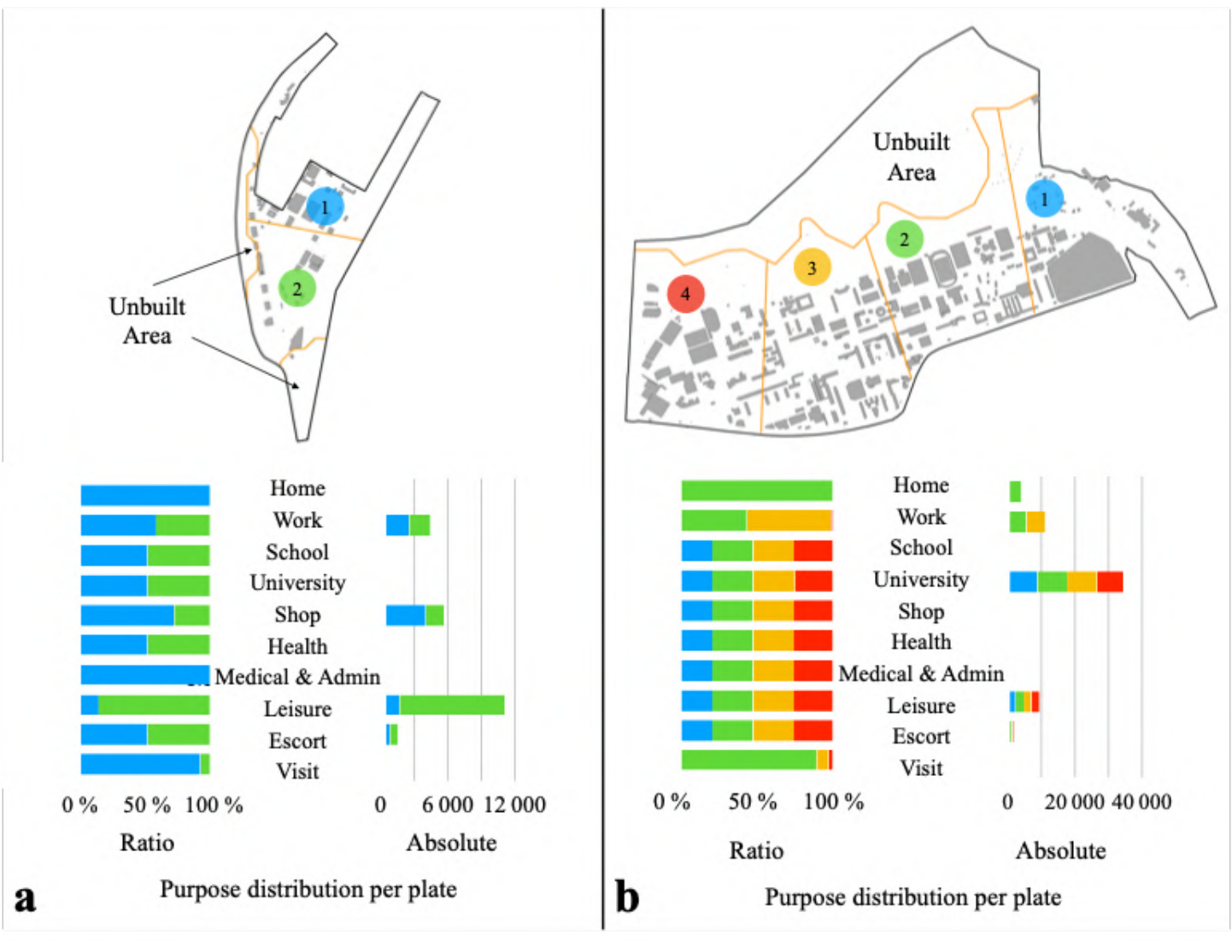

Figure 9: Results of the successive algorithms on two different areas: (a) "MontRocher" - a shop \& leisure area, (b) "La Doua" - a student area. Built is shown in dark gray, the orange line delimits FM-IRISes. The purpose distribution is also indicated as a ratio between the different FM-IRISes (left part of the graphs) and an absolute number of trips associated with the area (right part). The color code reflects different FM-IRISes.

\subsection{Experiment design}

After the FM-IRISes have been designed and after the purposes have been quantified, we used Symuvia ${ }^{3}$ as a trip-based dynamic simulator for calculating travel time in the traffic network. Symuvia is a microscopic simulator based on the Lagrangian resolution of the LWR model (Leclercq,2007). This car-following law has been further extended to account for all features of urban traffic: bounded acceleration (Leclercq, 2017), lane-changing with relaxation (Laval and Leclercq, 2008), multiclass (Leclercq and Laval, 2009), signalized and nonsignalized intersections (Chevallier and Leclercq, 2009a), roundabouts (Chevallier and Leclercq, 2009b), etc. All signalized intersections have been set up with their actual signal settings, including bus priority. The simulation timestep was equal to 1 second.

We chose to apply our methodology to an extraction of the Micro-Perimeter, shown in Figure 10 (colored TAZs) together with the Micro-Perimeter (light blue TAZs).

This extraction (shown explicitly in Figure 11) groups the $6^{\text {th }}$ district of Lyon, the $3^{\text {rd }}$ district of Lyon, and a part of Villeurbanne, covering about $18 \mathrm{~km}^{2}$. Lyon $6^{\text {th }}$ district is located on the east part of this extraction. It is mainly a residential area with shops and work activities, with a road network close to a Manhattan Network. It also includes one of the city's major commercial

\footnotetext{
${ }^{3}$ Note that Symuvia is an open source simulator freely available at https://github.com/Ifsttar/Open-SymuVia.
} 
areas in the southern border's vicinity. Lyon $3^{\text {rd }}$ district extent on the southern-eastern part. It is mainly residential, less downtown, and includes more diverse purposes, e.g., "Leisure", "Schools", and "College". The Villeurbanne area spreads over the northern part of the perimeter and is bordered by a high-capacity ring road. Villeurbanne city holds one of Lyon's largest universities and an extended campus (See the blue area in Figure 11a). Thus, many campusassociated purposes ("Leisure", "University", "Work") are located there.

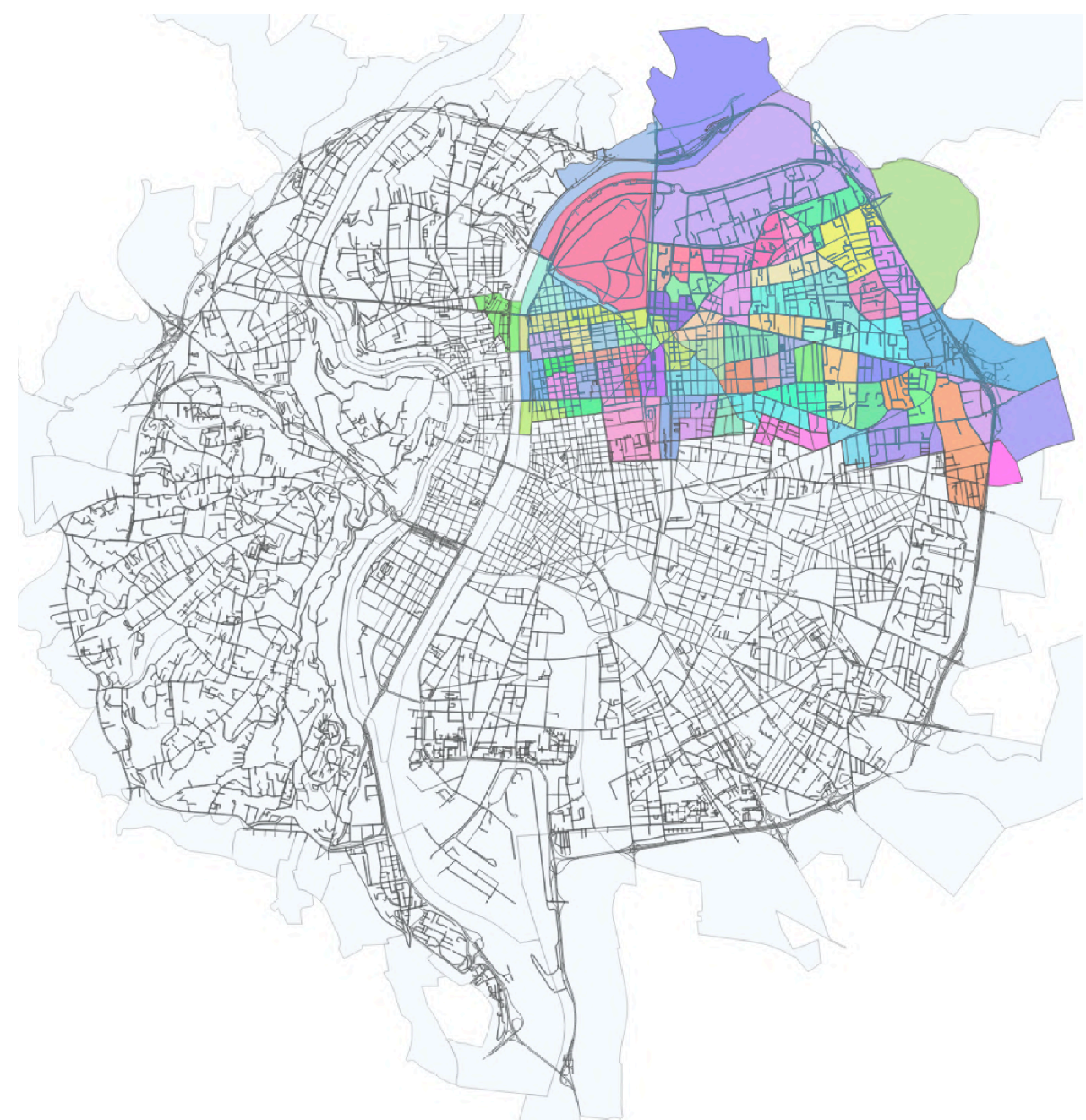

Figure 10: Illustration of the micro-perimeter with the TAZs (IRIS) in light blue. The extraction used for the experiment is highlighted with colored TAZs.

The framework (meaning demand estimation, FM-IRISes creation, and purposes distribution) was realized on the whole Macro-Perimeter. The experiment, however, was not realized on the Micro-Perimeter, but on a sub-area of this Micro-Perimeter. This is because it is technically very expensive to run the micro-simulator on the full city of Lyon. On several aspects (encoding the network, applying dynamic reassignment), simulating the full microperimeter would have been much more time-consuming, and it would not have a considerable impact, as we focus on very short-scale processes, defined by the purpose distribution at the city scale.

Thus, this network is composed of seventy-five IRIS Areas and slightly fewer than two hundred FM-IRISes. We ran the simulation to capture the full morning peak hour, from 7:00 am to 10:30 am, including a 30min warm-up period, from 6:30 am to 7:00 am. Traffic states 
were recorded every 10 minutes. As morning peak hour mobility is mainly composed of commuting employees, we expected many trips to terminate in working areas. Our simulation included dynamic reassignment, following Ameli et al., 2019, based on a 20min period. This meant that all OD pairs' path flow distributions were updated every $20 \mathrm{~min}$ based on the current traffic conditions (travel times) to achieve user equilibrium. We did not develop this aspect, which was out-of-the-scope of the present study.

We carried out two experiments. In the first one, the full methodology described in this paper was applied. This experiment is called experiment 1 in the following. In the second experiment (experiment 2), we deactivated the FM-IRISes. Travel demand is still computed from FSM (including census and purposes), but trip starting and terminating points were chosen randomly among the IRIS areas (control run). Experiment 2 was the current state-of-the-art for most of the micro simulations currently available (commercial or open-source). Thus, this experiment mimics any microsimulation that could be carried on after the demand has been estimated through a classical FSM.

In other words, the only difference between both experiments is the use (experiment 1) or not (experiment 2) of the proposed method to accurately locate trips starts and endings. In both experiments, purposes are used for defining the travel demand and the OD matrices between TAZs are strictly identical.

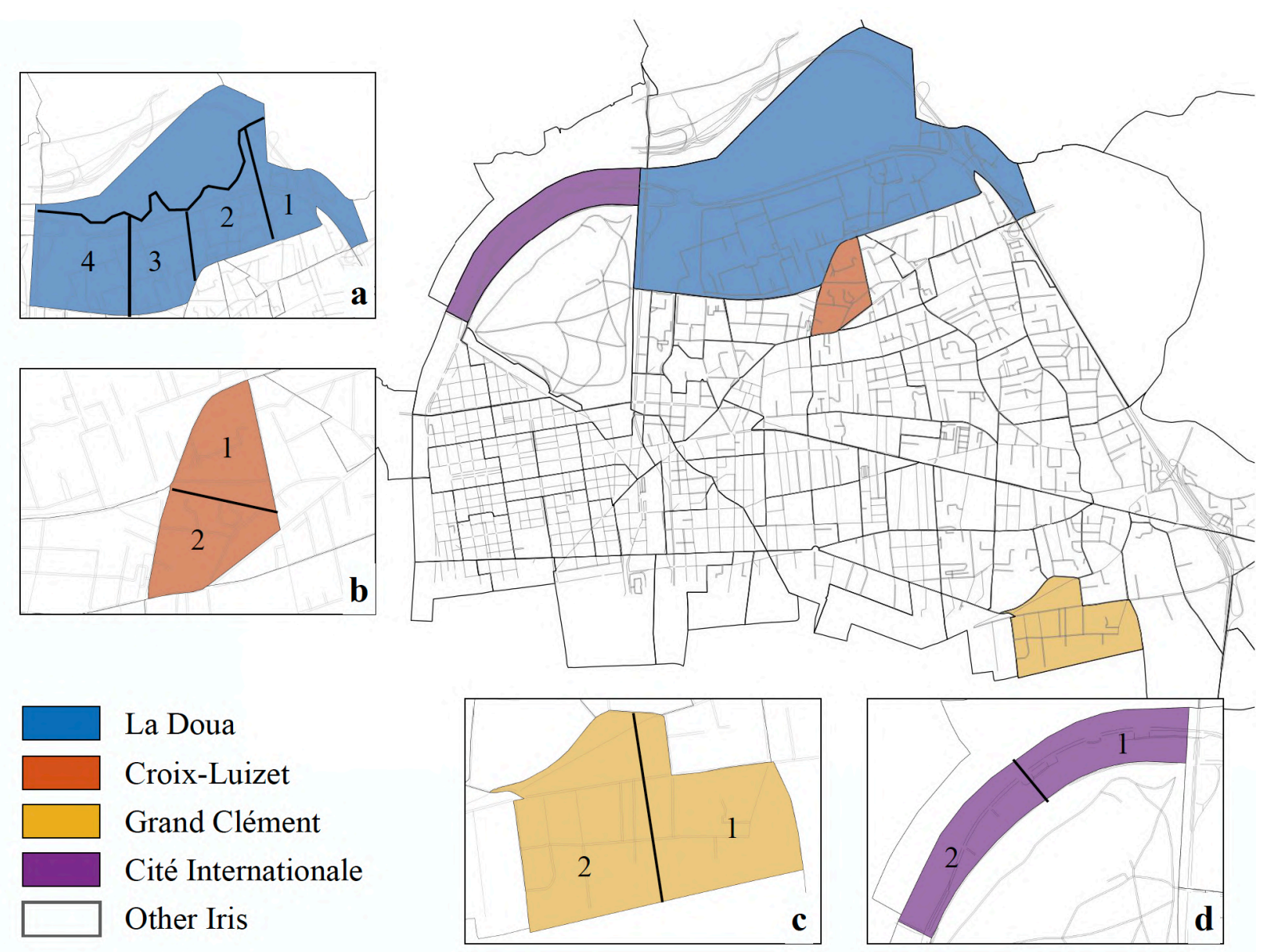

Figure 11: Illustration of the simulated network. IRISes are delimited with a thick black line, and four of them are colored: (a) La Doua (blue), (b) Croix-Luizet (red), (c) Grand Clément (yellow), and (d) Cité Internationale (purple) with FM-IRIS numbering written. 


\section{Results}

\subsection{Mean velocity variability}

We compare the evolution of the mean velocity averaged at the network scale as a function of time. The results of the two experiments are shown in Figure 12 below.

In both experiments, the first 45min (7:00 am to 7:45 am) show no significant difference. At this stage, demand is still low, growing slowly, and the network is mainly freeflow.

From 7:45 am, the demand increases strongly, corresponding to the start of morning peak activity. The network starts being loaded, and some congestion appears. Mean velocity thus decreases in both experiments. However, our study shows that in experiment 1 , the mean velocity decreases much faster and more intensely, reaching à minimum value of $32 \mathrm{~km} / \mathrm{h}$ at about 9:10 am, during the most congested period, while the mean velocity in experiment 2 does not decrease more than $35 \mathrm{~km} / \mathrm{h}$ at 9:20 am, with a slight variation.

In the morning, travelers mainly go to work (workers and students). In experiment 1 , localizing trip terminations to "Work", "School", "College" and "University" locations creates more local congestion that then propagates. It does not mean that refining the location of trip starts and endings increases congestion for any network but it is the case here. What is important to notice here is that such a process has a significant impacts when simulating the traffic conditions inside the network in particular during peak hours, meaning that it cannot be neglected when running microsimulations.

The velocity gap between both experiments reaches a maximum value of about $3.2 \mathrm{~km} / \mathrm{h}$ and remains up to 10:10 am, then decreases slowly, but remains up to the end of the simulation. This is explained by the fact that the global demand, even though decreasing at the end of the peak, still stays much higher between 9:30 am and 10:30 am than between 7:00 am and 8:00 am. 


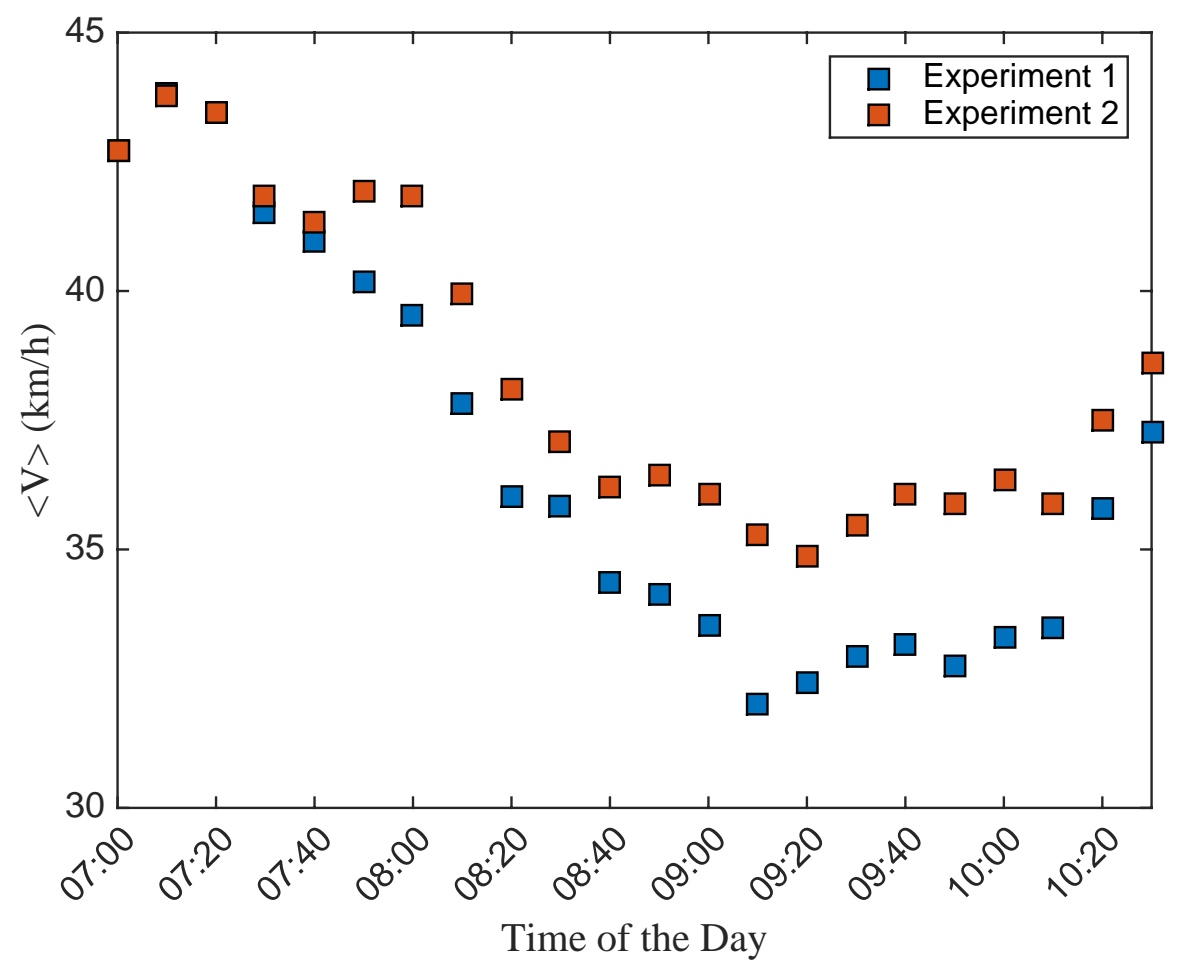

Figure 12: Evolution of the mean velocity, averaged at the network scale, as a function of time, in the case where FM-IRISes are activated (blue, experiment 1) and in the case where FMIRISes are unplugged (red, experiment 2). Experiment 2 is comparable to the classical FourStep Model setup.

\subsection{Impact of demand downscaling in terms of local traffic dynamics}

To better understand the difference between both experiments, we downscaled our analysis to the IRIS scale. Figure 13 shows a comparison between the average velocities in the two experiments for each IRIS area and each time interval. This figure highlights the mean velocities for four specific areas: La Doua, Croix-Luizet, Grand Clément, Cité Internationale. Figure 13 shows that for these areas, the mean velocity is higher in experiment 2 than in experiment 1, meaning that the distribution of trips at the FM-IRIS scale significantly changes the overall network performances predicted by microsimulation. 


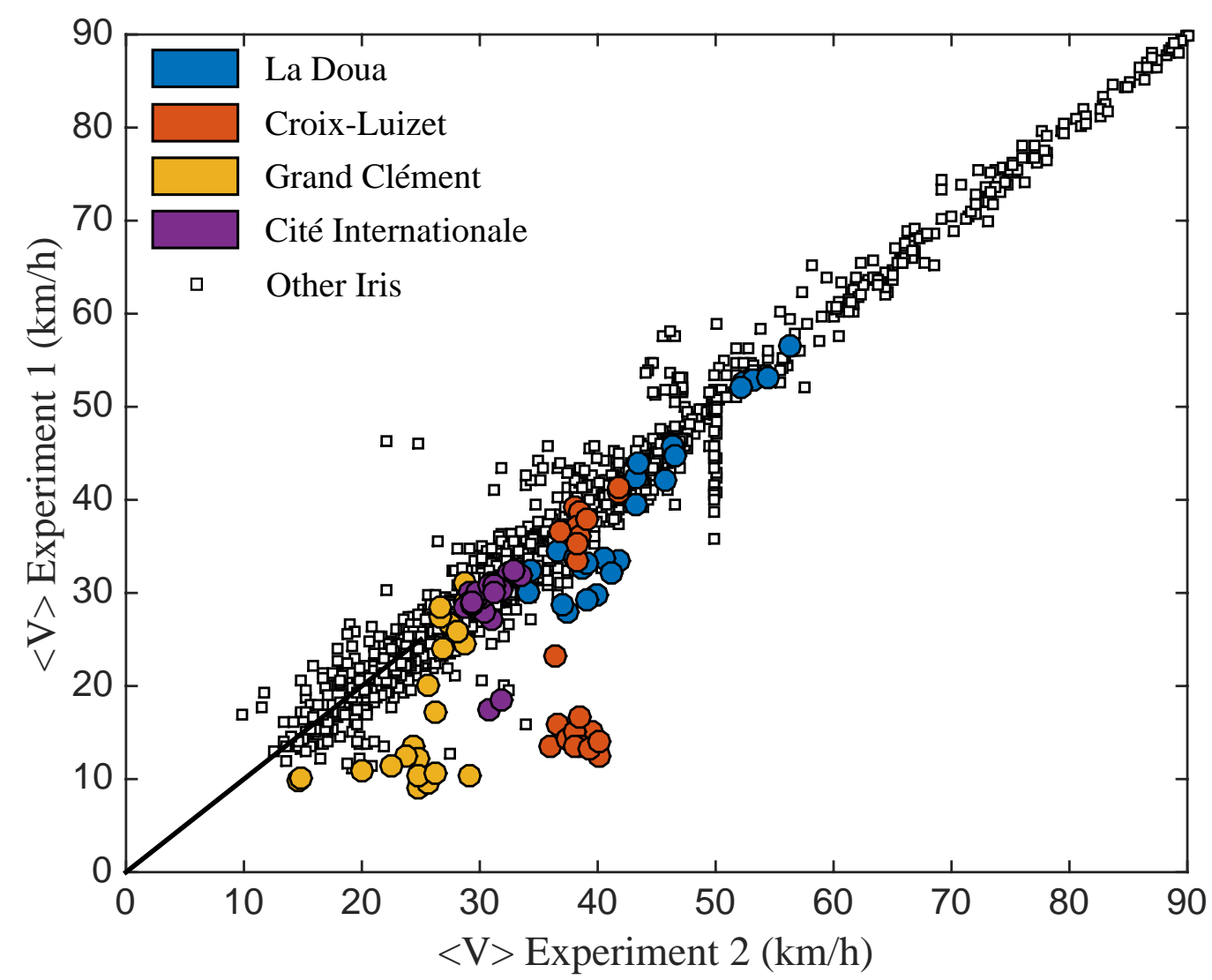

Figure 13: Comparison of FM-IRIS's effect on the mean velocity at the IRIS area scale, for all timesteps (every 10min). All IRIS areas are represented (white squares), and four of them are highlighted: La Doua (blue), Croix-Luizet (orange), Grand Clément (yellow), and Cité Internationale (purple).

The distribution of trip endings inside these four specific IRIS areas as a function of their purpose is illustrated in Figure 14 below. They can be located on the global map using Figure 11. Their behavior is explained in the following.

La Doua (Figure 14a) is one of the larger areas studied. It is viewed in-depth in Figure 9b, where we show that there is high variability in terms of purposes and demand level between its four FM-IRISes. Notably, the distribution of purpose "Work" is restricted to FM-IRIS 2 and 3, and "Home" is limited to FM-IRIS 2. In the simulation, most trips terminating with the purpose "Work" shares between FM-IRIS 2 and 3, gathering about 2000 trips. Practically, for trips ending with purpose "University", experiment 1 shows that vehicles are well balanced between the four FM-IRISes meaning about 2000 vehicles. In the case of this area, the other purposes are not significant. Finally, high traffic levels almost only occur in FM-IRIS 2 and 3, resulting in local congestion, spilling back over the neighbor area (see paragraph below).

Croix-Luizet (Figure 14b) is a downtown area located just south of La Doua. It is divided into two FM-IRISes in which the sharing of trips is quite distinct: most "Home" and "Leisure" are located in FM-IRIS 1 while "Work", "Medical \&Administrative Steps" and "Shop" purposes are located in FM-IRIS 2. During the morning peak hour, we see that the main flow of vehicles heads toward FM-IRIS 2, with the purpose "Work". However, micro-simulation shows that FM-IRIS 1 is the most used for accessing the La Doua area (especially FM-IRIS 2 and 3). Thus, if this area's velocity decreases strongly (as shown in Figure 13), this is mainly 
due to the congestion spillback coming from La Doua rather than the inequity of purposes distribution.

Grand Clément (Figure 14c) is located around the southern border of the network. However, it is a downtown area and an area with many inhabitants and services. Results show that the main flows are composed of "Work" and "College" purposes. "College" is mainly located in FM-IRIS 1 (250 vehicles), when "Work" is equally shared, even if over-represented in FMIRIS 1 (192 Vs. 150 vehicles). This results in many vehicles driving to FM-IRIS 1 (485) rather than FM-IRIS 2 (123) during morning peak hours. This unbalance increases the number of vehicles in small streets, leading to decreased network performance in the area.

Cité Internationale (Figure 14d) is an area dedicated to commercial centers, cinemas, and offices. Thus, most of the vehicles driving there are heading to "Work", "Shop", and "Leisure" purposes. However, "Leisures" are exclusively located in FM-IRIS 1, as well as most of "Work" (meaning 429 against 141). In this area, the unbalance is high (783 vehicles going to FM-IRIS 1 and 154 vehicles going to FM-IRIS 2), resulting in the appearance of local congestion and a decrease in the mean velocity, which reflects on the global network performance.

The four areas displayed in Figure 13 and 14 exhibit a significant modification of the mean velocity between experiment 1 and 2 . This highlights the sensitivity of local traffic dynamics to the trip terminal locations. It should be noticed that the decrease in velocity observed for these areas does not happen in every TAZ of the network. It highly depends on the distribution of purposes between the FM-IRISes. In our study, on average, the mean velocity is decreased.

The impact of distributing the purposes at the FM-IRIS level rather than choosing trip ending location randomly at the IRIS scale (like FSM usually does) will significantly affect vehicles' behavior at this microscopic scale. The global emission/attraction for a given IRIS area is not modified by our framework, as our method simply reorganizes the trip terminations inside the IRIS areas.

Through our numerical experiments (experiment 1 and experiment 2), we clearly show that refining the trip's start and end location matters as it may change the traffic conditions (mean spatial speed). It does not fully validate our method because we could not confirm that the trends match actual observations. If we think about exploiting the data we have, i.e., mainly loop detectors, it gives too few observations about the local trip behavior to be conclusive. The 660 loops inside Lyon city may look numerous, but they represent too few counts when tackling the assignment problem, i.e., determining the path distribution. This problem is highly underdetermined as we have about 90000 OD pairs with usually 5 to 10 viable paths, which means about 450000 variables compared with 660 observations! It is almost impossible to get the exact trip distribution at the city scale as many options can match the flow observations. It is a well-known problem that has not been tackled yet. We did such a calibration after applying our trip generation and termination step. If we would rerun the simulations using instead randomly distributed trip generations and terminations, it may increase the discrepancies between the simulation and the actual loop observations. However, this means nothing to our point of view. It would have been equally possible to get accurate fits between the simulation and loop data without applying our method simply because we have lots of freedom to play with the path flow distribution and get the observations we wish. Comparing mean speed would be very difficult, too, as loops only give access to local speeds related to flow counts that are not consistent with the mean spatial speed over the region. A complete validation of our method would require detailed trajectory data, at least over large areas, to investigate the actual location of trip starts and ends and correctly estimate mean speeds. However, collecting individual large-scale databases with high resolution for trip starting and ending is a real challenge and is almost 
impossible. Such action is out-of-the-scope of the current study, which focuses on designing the new methodology and assessing the impacts for microscopic simulations. Still, we consider that our simulations clearly show that we cannot keep this question of trip starts and endings under the radar because it strongly influences the simulation results. Furthermore, the proposed method looks very intuitive as it locates trips where they are more likely to appear and disappear considering the land-use data and purposes.
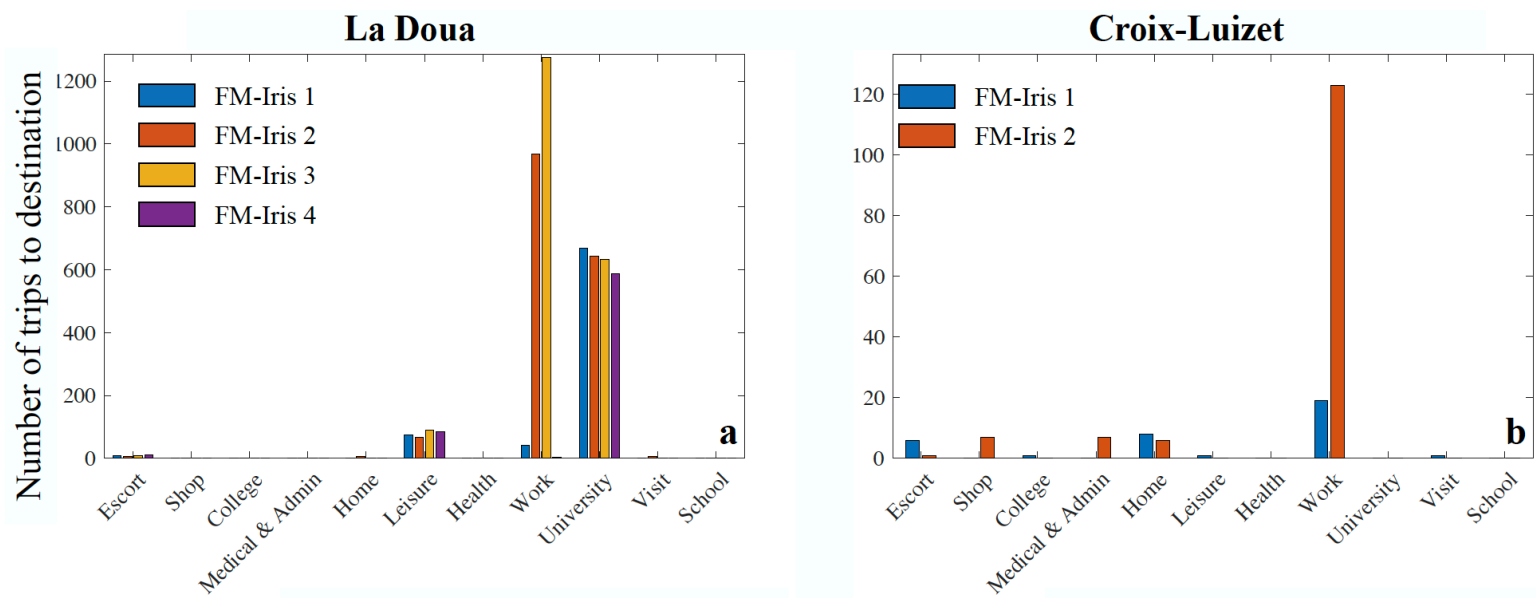

Grand Clément
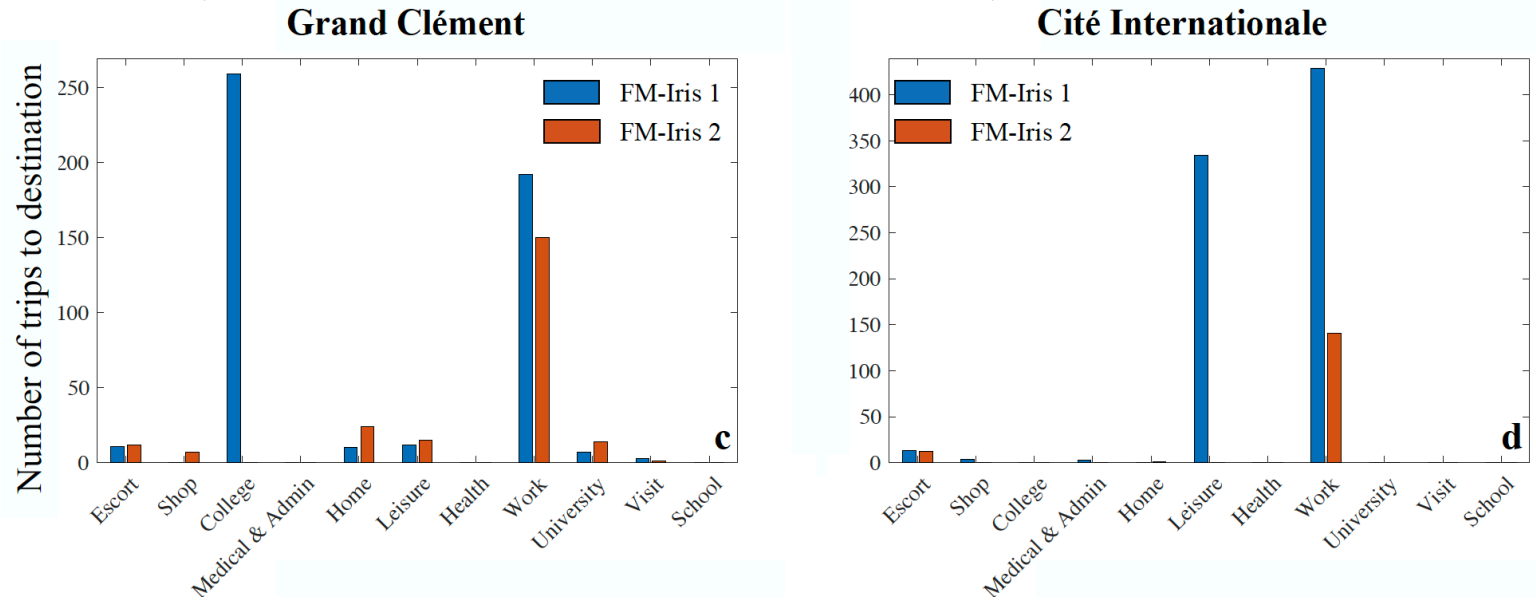

Figure 14: Sharing of trip termination in four IRIS areas (La Doua, Croix-Luizet, Grand Clément, Cité Internationale), distinguished by FM-IRIS in the case of experiment 1.

\section{Conclusion}

FSM applications to transportation studies range from urban planning to dynamic traffic simulation and traffic control. Usually, the estimation of demand relies on spatial areas in which mobility data, including travelers' socio-economic characteristics, are aggregated. Vehicles are then injected into the network from a series of virtual points distributed within the area.

However, when dealing with micro-scale dynamic simulations, this representation is misleading for two reasons: (i) the use of punctual virtual entries or exits may spatially distribute vehicles in a way that does not reflect reality, also (ii) the trip purposes at the origin and destination are generally not relevant.

To avoid these limitations in dynamic micro-simulations, we proposed to increase the description of trip characteristics by increasing the accuracy of the origin and destination of vehicles inside these areas and by correlating the new trip origins and destinations to real travel purposes. 
To achieve this objective, we combined nine public data sources, including household surveys and geo-referenced datasets given at the IRIS area's scale, with an accurate description of the built configuration. These data were associated with different algorithms and meshes of different finenesses, allowing us to downscale the demand to a more refined level.

Despite integrating a large number of purposes (11 purposes in our case), much than in the classical application of FSM (McNally, M.G., 2007, Wang et al., 2013, Apronti and Ksaibati, 2018, Park et al., 2019), our framework could still be improved by refining some purpose processing. As we rely on buildings to determine purposes, outside green areas do not appear as potential locations for trips' terminations. In Lyon's city, such a situation does not happen, except in the so-called "tête d'Or" central park neighborhood. It is the reason we pay little attention to this particular point. However, in other cities, not considering green areas may be more detrimental and must be considered. Our algorithm can be easily extended to account for such a situation if we include the real data in the process, i.e., the main green areas' location. Fortunately, such data are easily available.

After the demand was estimated at the IRIS level, the setup was integrated into Lyon, and a simulation was conducted on a local network included in the Lyon network. We decided to evaluate our methodology by focusing on subregions only because our motivations were to show consequences at a very small-scale (almost street-scale), rather than focus on a large-scale simulation (which would have largely increased network complexity and computational time). However, further studies should be applied to the full Lyon city to extend our conclusion at a very-large-scale, although this is very challenging for a micro-simulator.

Our current results showed that when the trip origin and destination are associated with an accurate trip location, the network's average performance is modified, compared to the case in which injection and extraction points are chosen randomly. In our case, mean velocity was thus lowered, and some local congestion appeared. However, we could expect contrary results depending on the FM-IRIS configuration. Congestion much depends on the location of activities in the city, and local phenomena can have severe consequences in terms of congestion spillback. The main conclusion here is that the locations of trip starts and ends have a significant influence on the overall traffic dynamics in microsimulation studies.

The proposed method would require further experimental validation to confirm the promising results we gained by simulation. However, as we explained earlier, it would require collecting individual large-scale trip database with high resolution for the trip starting and ending. Even at smaller scale and the experimental design would require considerable effort and may raise some privacy concerns about the data collected. The lack of field-validation does not undermine our study's conclusion as micro-simulation is often considered a good proxy for urban traffic dynamics. Our simulation experiments clearly showed the importance of accurately locating the trip purposes at a small-scale.

The transferability of our framework to other cities is quite straightforward. The only question is about data availability. Regarding original data used for the generation step of the Four-Step Model (Census, Household surveys, generic socio-economic data), most of them are usually available in many cities, areas, and countries, as illustrated by the available literature. Concerning the description of the purposes, all these data (RIL, SIRENE, BD address, and BD Topo) are freely available in France but maybe less accessible in other countries. This is especially true for the SIRENE file, which gathers data specific to the companies, that may not be made open-access. Finally, the capacity of schools, colleges, and universities, although there are partly available online, may still require an additional phone treatment that is timeconsuming. However, the mathematical process for estimating built areas and distribution of 
purposes at the FM-IRIS scale does not include technical difficulties. It is, in that way, quite transferrable to any micro-simulators.

\section{References}

Agence d'Urbanisme, SYTRAL, 2016. Enquète déplacements 2015 de l'aire métropolitaine lyonnaise. Résultat sur le Scot de l'agglomération lyonnaise. Agence d'Urbanisme, Lyon.

Altan, M. F., \& Ayözen, Y. E. (2018). The Effect of the Size of Traffic Analysis Zones on the Quality of Transport Demand Forecasts and Travel Assignments. Periodica Polytechnica Civil Engineering, 62(4), 971-979.

Ameli, M., Lebacque, J. P., Delhoum Y. \& Leclercq, L. (2019). Simulation-based user equilibrium: improving the fixed-point solution methods, In Transportation Research Board 98th Annual Meeting, Washington DC, USA.

Apronti, D. T., \& Ksaibati, K. (2018). Four-step travel demand model implementation for estimating traffic volumes on rural low-volume roads in Wyoming. Transportation planning and technology, 41(5), 557-571

Balmer, M., Axhausen, K. W., \& Nagel, K. (2006). Agent-based demand-modeling framework for large-scale microsimulations. Transportation Research Record, 1985(1), 125134.

Barton-Aschman Associates, I., Cambridge Systematics, I., 1997. Model Validation and Reasonableness Checking Manual. Washington, DC.

Batterman, S., Chambliss, S., \& Isakov, V. (2014). Spatial resolution requirements for traffic-related air pollutant exposure evaluations. Atmospheric environment, 94, 518-528.

Binetti, M., \& Ciani, E. (2002). Effects of traffic analysis zones design on transportation models. In Proceedings of the 9th Meeting of the Euro Working Group on Transportation, Bari, Italy.

Ben-Akiva, M.E., Lerman, S.R., 1985. Discrete choice analysis: theory and application to travel demand. MIT press.

Bonnel, P., 2002. Prévision de la demande de transport. Université Lumière-Lyon II.

Cabrera Delgado, J., Bonnel, P., 2016. Level of aggregation of zoning and temporal transferability of the gravity distribution model: The case of Lyon. J. Transp. Geogr. 51, 1726. https://doi.org/10.1016/j.jtrangeo.2015.10.016.

Chevallier, E., Leclercq, L., 2009a. Do microscopic merging models reproduce the observed priority sharing ratio in congestion? Transportation research part C, 17(3):328-336.

Chevallier, E., Leclercq, L., 2009b. A microscopic dual-regime model for single-lane roundabouts. Journal of Transportation Engineering, 135(6):386-394.

Ding, C. (1998). The GIS-based human-interactive TAZ design algorithm: examining the impacts of data aggregation on transportation-planning analysis. Environment and Planning B: Planning and Design, 25(4), 601-616.

Dowd, M.G., 2015. Modeling inundation impacts on transportation network performance: a GIS and four-step transportation modeling analysis. Massachusetts Institute of Technology.

Ghadiri, M., Rassafi, A. A., \& Mirbaha, B. (2019). The effects of traffic zoning with regular geometric shapes on the precision of trip production models. Journal of Transport Geography, 78, 150-159.

Gurram, S., Stuart, A. L., \& Pinjari, A. R. (2019). Agent-based modeling to estimate exposures to urban air pollution from transportation: Exposure disparities and impacts of highresolution data. Computers, Environment and Urban Systems, 75, 22-34. 
Hagen-Zanker, A., \& Jin, Y. (2015, June). Adaptive zoning for efficient transport modelling in urban models. In International Conference on Computational Science and Its Applications (pp. 673-687). Springer, Cham.

Horowitz, A. J. (2001). Computational issues in increasing spatial precision of traffic assignments. Transportation research record, 1777(1), 68-74.

INSEE, 2016. Définition - Répertoire d'immeubles localisés / RIL / RIL | Insee [WWW Document]. URL https://www.insee.fr/fr/metadonnees/definition/c1815 (accessed 5.14.18).

Jeon, J. H., Kho, S. Y., Park, J. J., \& Kim, D. K. (2012). Effects of spatial aggregation level on an urban transportation planning model. KSCE Journal of Civil Engineering, 16(5), 835844.

Laval, J.A., Leclercq, L., 2008. Microscopic modeling of the relaxation phenomenon using a macroscopic lane-changing model. Transp. Res. Part B Methodol. 42, 511-522.

Leclercq, L., 2007. Bounded acceleration close to fixed and moving bottlenecks. Transp. Res. Part B Methodol. 41, 309-319.

Leclercq, L., Laval, J.A., 2009. A multiclass car-following rule based on the LWR model, in: Traffic and Granular Flow'07. Springer, pp. 151-160.

Lovelace, R., Ballas, D., \& Watson, M. (2014). A spatial microsimulation approach for the analysis of commuter patterns: from individual to regional levels. Journal of Transport Geography, 34, 282-296.

Lund, A. M., Gouripeddi, R., \& Facelli, J. C. (2020). STHAM: an agent based model for simulating human exposure across high resolution spatiotemporal domains. Journal of Exposure Science \& Environmental Epidemiology, 30(3), 459-468.

Martínez, L. M., Viegas, J. M., \& Silva, E. A. (2007). Zoning decisions in transport planning and their impact on the precision of results. Transportation Research Record, 1994(1), 58-65.

Martínez, L. M., Viegas, J. M., \& Silva, E. A. (2009). A traffic analysis zone definition: a new methodology and algorithm. Transportation, 36(5), 581-599.

Martínez, L. M., Dupont-Kieffer, A., \& Viegas, J. M. (2010, July). An integrated application of zoning for mobility analysis and planning: the case of Paris Region.

Manheim, M.L., 1979. Fundamentals of Transportation systems analysis; Volume 1: Basic concepts.

Manout, O., Bonnel, P., Bouzouina, L., 2018. Transit accessibility: A new definitionof transit connectors. Transportation Research Part A: Policy and Practice 113, 88-00. https://doi.org/10.1016/j.tra.2018.03.028

Manout, O., \& Bonnel, P. (2019). The impact of ignoring intrazonal trips in assignment models: a stochastic approach. Transportation, 1-21.

McNally, M.G., 2007. The four-step model, in: Handbook of Transport Modelling: 2nd Edition. Emerald Group Publishing Limited, pp. 35-53.

Moeckel, R., Schürmann, C., \& Wegener, M. (2002, August). Microsimulation of urban land use. In 42nd European Congress of the Regional Science Association, Dortmund (pp. 2731).

Openshaw, S., 1977. Optimal zoning systems for spatial interaction models. Environ. Plan. A 9, 169-184.

Pachauri, R. K., Allen, M. R., Barros, V. R., Broome, J., Cramer, W., Christ, R., ... \& Dubash, N. K. (2014). Climate change 2014: synthesis report. Contribution of Working Groups I, II and III to the fifth assessment report of the Intergovernmental Panel on Climate Change (p. 151). Ipcc.

Páez, A., \& Scott, D. M. (2004). Spatial statistics for urban analysis: a review of techniques with examples. GeoJournal, 61(1), 53-67.

Park, K., Sabouri, S., Lyons, T., Tian, G., \& Ewing, R. (2019). Intrazonal or interzonal? Improving intrazonal travel forecast in a four-step travel demand model. Transportation, 1-22. 
Patriksson, M., 2015. The traffic assignment problem: models and methods. Courier Dover Publications.

Qian, Z. S., \& Zhang, H. M. (2012). On centroid connectors in static traffic assignment: Their effects on flow patterns and how to optimize their selections. Transportation Research Part B: Methodological, 46(10), 1489-1503.

Supernak, J., 1983. Transportation modeling: lessons from the past and tasks for the future. Transportation 12, 79-90.

Toilier, F., Gardrat, M., Routhier, J. L., \& Bonnafous, A. (2018). Freight transport modelling in urban areas: The French case of the FRETURB model. Case Studies on Transport Policy, 6(4), 753-764.

Viegas, J.M., Martinez, L.M., Silva, E.A., 2009. Effects of the modifiable areal unit problem on the delineation of traffic analysis zones. Environ. Plan. B Plan. Des. 36, 625-643.

Wang, T., A. Gan, and A. Priyanka. 2013. "Estimating Annual Average Daily Traffic for local Roads for Highway Safety Analysis." Journal of the Transportation Research Board 2398: 60-66.

Wegener, M. (2011). From macro to micro-how much micro is too much?. Transport Reviews, 31(2), 161-177.

Zhang, L., Levinson, D.M., 2016. A model of the rise and fall of roads.

Zhao, Y., Kockelman, K.M., 2002. The propagation of uncertainty through travel demand models: an exploratory analysis. Ann. Reg. Sci. 36, 145-163.

Zhao, Y., \& Kockelman, K. (2000). The propagation of uncertainty through travel demand models (No. SWUTC/00/167804-1). Southwest Region University Transportation Center, Center for Transportation Research, University of Texas. 